\title{
Towards balancing in-plane mechanical properties and impact damage tolerance of composite laminates using quasi-UD woven fabrics with hybrid warp yarns DOI:
}

10.1016/j.compstruct.2019.111083

\section{Document Version}

Accepted author manuscript

Link to publication record in Manchester Research Explorer

Citation for published version (APA):

Katnam, K. B., Dalfi, H., \& Potluri, P. (2019). Towards balancing in-plane mechanical properties and impact damage tolerance of composite laminates using quasi-UD woven fabrics with hybrid warp yarns. Composite Structures, 225, [111083]. https://doi.org/10.1016/j.compstruct.2019.111083

Published in:

Composite Structures

\section{Citing this paper}

Please note that where the full-text provided on Manchester Research Explorer is the Author Accepted Manuscript or Proof version this may differ from the final Published version. If citing, it is advised that you check and use the publisher's definitive version.

\section{General rights}

Copyright and moral rights for the publications made accessible in the Research Explorer are retained by the authors and/or other copyright owners and it is a condition of accessing publications that users recognise and abide by the legal requirements associated with these rights.

\section{Takedown policy}

If you believe that this document breaches copyright please refer to the University of Manchester's Takedown Procedures [http://man.ac.uk/04Y6Bo] or contact uml.scholarlycommunications@manchester.ac.uk providing relevant details, so we can investigate your claim.

\section{OPEN ACCESS}




\title{
Towards balancing in-plane mechanical properties and impact damage tolerance of composite laminates using quasi-UD woven fabrics with hybrid warp yarns
}

\author{
K. B. Katnam ${ }^{1}$, H. Dalfi ${ }^{2}$, P. Potluri ${ }^{2}$ \\ ${ }^{1}$ School of Mechanical, Aerospace and Civil Engineering, University of Manchester, UK \\ ${ }^{2}$ The Northwest Composites Centre, School of Materials, University of Manchester, UK
}

\begin{abstract}
An experimental study is conducted with the aim of balancing in-plane mechanical properties and impact damage tolerance in composite woven laminates using a quasi-unidirectional (quasi-UD) woven fabric (i.e. low crimp architecture) and yarn-level fibre hybridisation. In this work, composite laminates are manufactured with and without yarn-level hybridisation and yarn crimp. By combining highstrength fibres (i.e. S-glass) and high-elongation fibres (i.e. polypropylene, PP) with commingling and core-wrapping processes, hybrid S-glass/PP yarns are produced. A quasi-UD fabric is then produced with unbalanced warp and weft yarns (i.e. $5 \mathrm{H}$ satin with high linear density hybrid S-glas/PP warp and low linear density S-glass weft yarns), and subsequently laminates are manufactured using vacuumassisted resin infusion. In addition, hybrid S-glass/PP yarns are used to manufacture non-crimp (i.e. without weft yarns) and $5 \mathrm{H}$ satin fabric (i.e. with balanced S-glass/PP warp and weft yarns) laminates. For comparison, S-glass yarns are used to manufacture non-crimp cross-ply laminates (i.e. without yarn-level hybridisation and without weft yarns). For all the laminates, the in-plane mechanical properties are measured by using tensile and compresive tests, and the low velocity impact response is investigated using drop-weight impact tests with different energy levels (i.e. 15, 25, 35 and $50 \mathrm{~J}$ ). Furthermore, the impact damage tolerance is characterised by measuring residual compressive strengths with compression-after-impact tests. The damaged specimens are investigated using scanning electron microscopy to identify inter- and intra-laminar failure mechanisms. The results indicate that the quasi-UD woven fabric composites with low crimp and yarn-level hybridisation can be successfully used to introduce conducive fibre architecture and microstructures to balance in-plane mechanical properties and impact damage tolerance.
\end{abstract}

Keywords: 2D woven hybrid composites; yarn-level fibre hybridisation; damage tolerance; low velocity impact damage; residual compressive strength; toughening mechanisms.

\section{Introduction}

Advanced composites are being used in several load-bearing applications as lighter designs can be achieved because of their high stiffness and strength to weight ratios - enabling fuel-efficiency, energyefficiency and reduced emissions. Conventional uni-directional pre-preg based composite laminates provide excellent in-plane mechanical properties (e.g. stiffness and strength in tension, compression and flexure), but their damage tolerance is still a major challenge to ensure structural integrity, especially in safety critical applications [1]. Composite laminates are in general susceptible to out-of-plane impact loading because of their inherent brittle intra-lamina and inter-lamina failure mechanisms (e.g. matrix cracking, fibre-matrix debonding, fibre breakage and delamination). Out-of-plane blunt impact loading introduces considerable sub-surface damage, which is barely visible near the point of impact, and leads to damage propagation and significantly affect the strength of damaged components (i.e. post-impact residual strength) [2]. In this regard, achieving a balance between in-plane mechanical properties and impact damage tolerance, which are in general mutually exclusive properties [3, 4], has been a key challenge to ensure post-impact structural integrity $[2,5]$.

As the mechanical properties of reinforced composites largely depend on the type of reinforcing fibres, their content (i.e. fibre volume fraction), placement and distribution (i.e. microstructure), textile pre- 
forms (e.g. 2D and 3D woven fabrics) are widely employed to explore different fibre interlacements for achieving desired architectures [6,7]. A significant amount of research conducted on textile composite laminates studying their in-plance mechanical properties, impact behaviour and damage tolerance has shown that superior impact damage tolerance and resistance compared to uni-directional pre-preg based laminates can be achieved [8-12]. Moreover, in recent years, several approaches to introduce through-thickness reinforcements are explored to further enhance damage tolerance in textile laminates, e.g. z-pinning, tufting, orthogonal and angular interlocking binder yarns can be used to supress delamination and improve impact damage tolerance [13-18]. However, one major disadvantage with textile composite laminates in general is that the in-plane mechanical properties (e.g. stiffness and strength in tension and compression) are compromised owing to the interlacing of fibres (i.e. high crimp architectures) and matrix-rich regions.

In recent years, hybrid composite laminates have been extensively explored to introduce hybrid effects at multiple lengthscales for tailoring intra- and inter-laminar properties. Novel material systems and manufacturing processes have been proposed and studied, e.g. matrix-toughening routes via nano-, micro- and/or macro-scale mechanisms [19-24] and fibre architectures via hybrid textile preforms [2527]. Recent studies have shown that an effective approach to enhance the impact performance of woven composite laminates is to use hybrid fibre systems - by combining either different fabric types (i.e. hybrid layup) or different warp and fill yarns (i.e. hybrid weave), or commingled fibres (i.e. hybrid yarns) [2830]. In addition, hybrid matrix systems, e.g. nano- or micro-particle modified thermoset resins and nonwoven thermoplastic interlayers, could provide opportunities to manipulate failure mechanisms at multiple length scales [31]. Although these hybrid matrix systems could be used to enhance the impact performance of thermoset composite laminates, there are a few issues with hybrid matrix systems, e.g. non-uniform dispersion of nano-fillers, high viscosity of nano-modified resins, and increased laminate thickness with interlayers. While most of these novel materials and processes could offer opportunities to enhance material properties, it is important to develop cost-effective approaches by exploring low cost raw materials and manufacturing processes as the usage of advanced composites has recently seen a significant growth in several engineering applications.

To improve the in-plane mechanical properties of woven composite laminates, low-crimp hybrid woven fabrics could offer new possibilities to manipulate intra-lamina fibre architecture and microstructures. For example, uni-directional woven fabrics, with an unbalanced $2 \mathrm{D}$ weave pattern with thin weft yarns, can be used to reduce fibre waviness in the warp yarns and minimize the reduction in in-plane laminate mechanical properties [32-34]. While the warp yarns provide in-plane loading capability, the thin weft yarns can also improve fabric integrity for handing and will play a role on damage initiation and propagation. In this context, this research paper is focused on balancing the in-plane mechanical properties and impact damage tolerance in $2 \mathrm{D}$ woven laminates by introducing toughening mechanisms via yarn-level fibre hybridisation - at the same time aiming to combine cost-effectiveness and proccessability. The paper investigates the impact damage tolerance of composite laminates made of hybrid quasi-unidirectional woven fabrics with hybrid warp yarns (i.e. S-glass commingled with commodity polypropylene fibres without surface treatment). The poor fibre-matrix interface adhesion of polypropylene fibres in the commingled yarns are exploited to introduce failure mechanisms that are conducive to energy dissipation, and subsequently to enhance the impact performance of the hybrid laminates. The in-plane mechanical properties and impact damage tolerance of the hybrid quasiunidirectional woven fabric based laminates is compared with those of the hybrid non-crimp, nonhybrid non-crimp and hybrid crimp fabric based laminates. The materials processing, manufacturing and testing techniques used are presented, and the role of yarn-level fibre hybridisation and fibre-architecture on balancing in-plane mechanical properties and impact performance in such laminates is discussed.

\section{Materials and Manufacturing}

\subsection{Yarn Hybridisation: Commingling and Core-wrapping Processes}

A combined commingling and core-wrapping process is employed for producing hybrid yarns using two continuous fibre types: high-strength S-glass yarns (supplied by AGY Industries UK) and highelongation polypropylene (PP) yarns (supplied by Drake Extrusion UK). The S-glass yarn is supplied 
with a linear density of 33 tex, a filament count of 207, and a fibre diameter of $9 \mu \mathrm{m}$; and the PP yarn with a linear density of 17 tex, a filament count of 40 , and a fibre diameter of $24 \mu \mathrm{m}$. The S-glass fibre surface has an epoxy compatible sizing; whereas, the PP fibre surface has no surface treatment.

Moreover, the PP yarn has relatively low density, low tenacity and large elongation in comparison with the S-glass yarn. The two yarn are commingled by passing them through an air-jet nozzle for producing hybrid yarns. The feed and delivery roller speeds used in the commingling process are $10.4 \mathrm{~m} / \mathrm{s}$ and 10 $\mathrm{m} / \mathrm{s}$, respectively, with an overfeed ratio of $4 \%$ and 2 bar air pressure in the nozzle. These commingling process parameters are optimised for the two yarns used, which has been reported by the authors elsewhere. Hybrid S-glass/PP core yarns are produced by commingling 15 S-glass yarns and 6 PP yarns with the air-jet nozzle; and subsequently the commingled core yarn is wrapped with a PP yarn in a twisting machine (Direct Twist, Agteks, Turkey) with 110 turns per meter. The commingled corewrapped S-glass/PP yarn has a linear density of 636 tex. In addition, for eliminating filament damage during manufacturing, a total of 19 S-glass yarns are twisted, which is to, with 30 turns per meter to produce a twisted S-glass yarn with linear density of 624 tex.

Table 1: The properties of S-glass, PP, twisted S-glass and commingled S-glass/PP yarns

\begin{tabular}{llllll}
\hline Yarn type & $\begin{array}{l}\text { Linear } \\
\text { density } \\
(\text { tex })\end{array}$ & $\begin{array}{l}\text { Fibre } \\
\text { diameter } \\
(\boldsymbol{\mu m})\end{array}$ & $\begin{array}{l}\text { Filament } \\
\text { count }\end{array}$ & $\begin{array}{l}\text { Yarn } \\
\text { tenacity } \\
\text { (cN/tex) }\end{array}$ & $\begin{array}{l}\text { Elongation } \\
(\mathbf{0})\end{array}$ \\
\hline S-glass & 33 & 9 & 207 & $79.3 \pm 19.8$ & $3.8 \pm 0.2$ \\
Polypropylene (PP) & 17 & 24 & 40 & $33.8 \pm 2.6$ & $111.3 \pm 7.3$ \\
Twisted S-glass & 624 & 9 & 3726 & $65.5 \pm 15.7$ & $3.9 \pm 0.3$ \\
Commingled S-glass/PP & 636 & $9 / 24$ & 3385 & $67.0 \pm 6.7$ & $4.4 \pm 0.3$ \\
\hline
\end{tabular}

To measure the yarn tenacity and elongation, standard tensile tests are conducted, according to ASTM D2256-2, with a gauge length of $250 \mathrm{~mm}$ and at a rate of $0.2 \mathrm{~mm} / \mathrm{s}$, on the yarns. The properties measured for the S-glass yarns, PP yarns, core-wrapped commingled S-glass/PP yarns and twisted Sglass yarns are given in Table 1 . It can be seen that the PP yarn has relatively low tenacity $(\sim 34 \mathrm{cN} /$ tex $)$ and high elongation $(\sim 110 \%)$ in comparison with the tenacity and elongation of the S-glass yarn ( $\sim 80$ $\mathrm{cN} /$ tex and $\sim 4 \%$, respectively). Moreover, the tenacity of the commingled S-glass/PP yarn $(\sim 67$ $\mathrm{cN} /$ tex $)$ is close to that of the twisted S-glass ( $\sim 65 \mathrm{cN} /$ tex $)$, while a considerable difference in elongation is observed (i.e. $\sim 4.4 \%$ for the commingled S-glass/PP yarn and $\sim 3.9 \%$ for the twisted Sglass yarn). From the measured yarn tenacities, it is worth noting that the standard deviation observed for the S-glass and twisted S-glass yarns is considerably higher than that for the PP and S-glass/PP yarns, suggesting that the presence of the high elongation PP fibres reduce the brittle behaviour of the Sglass yarns. Note that additional tensile tests conducted on untwisted S-glass yarns have confirmed that the twist level used (at 30 turns per meter) for the S-glass yarns has negligible effect on the yarn tenacity and elongation. The twisted S-glass fabric based laminates are thus used as a baseline in order to compare with the commingled S-glass/PP fabric based laminates.

\subsection{Fibre Architecture and Weaving Process}

As the aim is to manufacture composite laminates with low crimp (i.e. fibre waviness) and yarn-level fibre hybridisation for balancing in-plane properties and impact damage tolerance, the weave architecture considered in this study is a quasi-unidirectional (quasi-UD) hybrid woven fabric. In this regard, two hybrid woven fabrics are produced: (a) a quasi-UD fabric with a $5 \mathrm{H}$ satin weave using unbalanced warp and weft yarns (i.e. hybrid S-glass/PP yarns with 636 tex as warp and S-glass yarns with 33 tex as weft, as shown in Fig.1a, denoted as S-glass/PP quasi-UD) and (b) a hybrid 5H satin fabric using balanced warp and weft yarns (i.e. hybrid S-glass/PP yarn with 636 tex as warp and weft, as shown in Fig.1b, denoted as S-glass/PP 5H satin) are produced for varying yarn crimp considering hybrid warp yarns. Moreover, two non-crimp architectures are produced using: (a) twisted S-glass yarns (denoted as S-glass UD) and (b) hybrid S-glass/PP yarns (denoted as S-glass/PP UD) for varying yarnlevel hybridisation considering non-crimp yarns. 

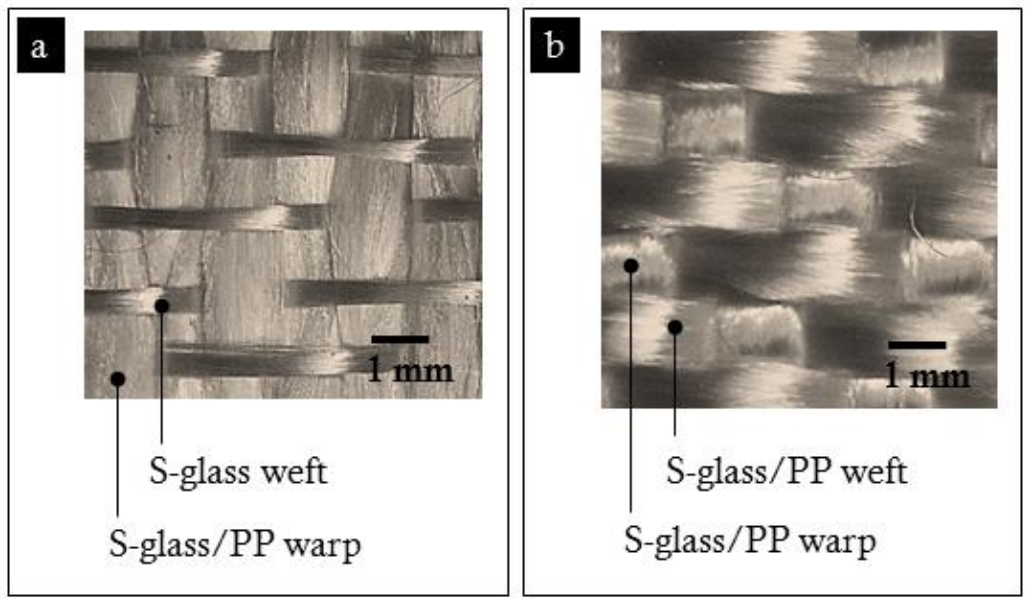

Figure 1: The weave pattern in: (a) quasi-UD hybrid $5 H$ satin fabric with unbalanced S-glass /PP warp and Sglass weft yarns (i.e. S-glass /PP quasi-UD) and (b) hybrid $5 H$ satin fabric with balanced S-glass/PP warp and weft yarns (i.e. S-glass/PP $5 H$ satin).

The S-glass/PP quasi-UD fabric consists of thin S-glass weft yarns interlacing hybrid S-glass/PP warp yarns - resulting in an unbalanced $5 \mathrm{H}$ satin weave with reduced fibre waviness and consisting of more than $90 \%$ hybrid S-glass/PP warp yarns while thin S-glass weft yarns offer fabric integrity. The Sglass/PP quasi-UD and S-glass/PP 5H satin fabric are produced using hand and power looms, respectively. The S-glass UD and S-glass/PP UD non-crimp preforms are produced (without weft yarns) using a robotic tow placement machine developed at the University of Manchester [30]. The counts in the warp and weft directions for all the preforms are 8 ends $/ \mathrm{cm}$ and 8 picks $/ \mathrm{cm}$, respectively. The fabric count, areal density, crimp level, and thickness are measured according to ASTM standards (i.e. D3775-02, D3776-09, D3883-04 and D1777-09), respectively, and are given in Table 2. The yarn crimp is significantly lower ( $\sim 60 \%)$ in the S-glass/PP quasi-UD fabric ( $\sim 1.45 \%$ crimp in warp direction) compared to that of the S-glass/PP $5 \mathrm{H}$ satin fabric ( $\sim 3.5 \%$ and $\sim 3.8 \%$ in warp and weft directions), and the areal density of the S-glass/PP quasi-UD fabric is considerably higher $(\sim 8 \%)$ with the presence of thin S-glass weft yarns. An areal density of approximately $1050 \mathrm{~g} / \mathrm{m}^{2}$ is also obtained for the S-glass UD and S-glass/PP UD preforms made of the hybrid S-glass/PP and twisted S-glass yarns.

Table 2: The properties of the woven preforms used for composite manufacturing

\begin{tabular}{lllll}
\hline 2D preform & $\begin{array}{l}\text { Areal density } \\
\left(\mathrm{g} / \mathbf{m}^{\mathbf{2}}\right)\end{array}$ & $\begin{array}{l}\text { Thickness } \\
(\boldsymbol{\mu m})\end{array}$ & $\begin{array}{l}\text { Crimp (\%) } \\
(\mathbf{w a r p})\end{array}$ & $\begin{array}{l}\text { Crimp (\%) } \\
(\mathbf{w e f t})\end{array}$ \\
\hline S-glass/PP quasi-UD & $1160^{*}$ & $1120^{*}$ & $1.44 \pm 0.31$ & - \\
S-glass/PP 5H satin & 1060 & 1100 & $3.51 \pm 0.15$ & $3.80 \pm 0.12$ \\
\hline
\end{tabular}

${ }^{*}$ Two layers

\subsection{Composite Laminate Manufacturing}

Composite laminates were produced using the $2 \mathrm{D}$ woven and non-crimp preforms produced (i.e. Sglass/PP quasi-UD, S-glass/PP 5H satin, S-glass/PP UD and S-glass UD preforms). To manufacture Sglass/PP $5 \mathrm{H}$ satin fabric laminates, the fabric is cut $(250 \mathrm{~mm} \times 250 \mathrm{~mm}$ in size $)$ and 4 plies are stacked (with warp yarns in 0/90/0/90 direction) to produce laminates using vacuum assisted resin infusion. A low viscosity epoxy resin (Araldite LY 564 and Ardur 2954 with a mix ratio of 100:35 by weight) is used with a recommend cure cycle $\left(120\right.$ minutes at $80^{\circ} \mathrm{C}$ and followed by 8 hours at $\left.140^{\circ} \mathrm{C}\right)$. In addition, S-glass/PP quasi-UD, S-glass/PP UD and S-glass UD laminates are manufactured using a balanced $[0 / 90]_{4}$ layup (i.e. 8 plies) - representing each ply in the S-glass/PP $5 \mathrm{H}$ satin fabric laminates with [0/90] quasi-UD or UD plies (see Fig. 2). The cured composite laminate panels were then machined with a diamond cutter to produce the test specimens. 

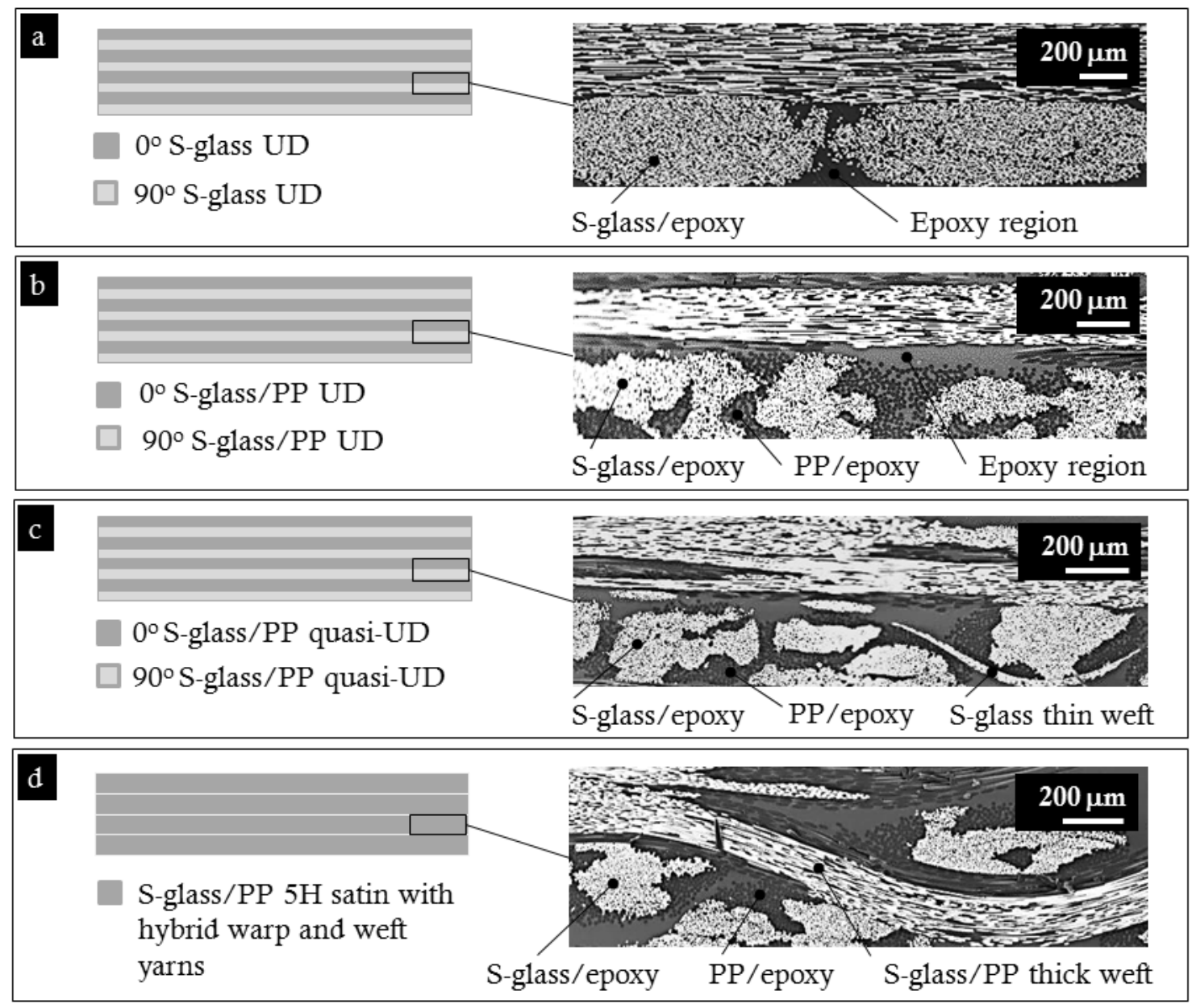

Figure 2: The fibre achitechtures and microstructures in the laminates manufactured with: (a) non-hybrid noncrimp preform (S-glass UD), i.e. with twisted S-glass yarns, (b) hybrid non-crimp preform (S-glass/PP UD), i.e. with commingled core-wrapped S-glass/PP yarns, (c) quasi-UD $5 H$ satin fabric (S-glass /PP quasi-UD), i.e. with unbalanced S-glass/PP warp and S-glass weft yarns, and (d) hybrid $5 H$ satin (S-glass/PP 5H satin), i.e. with balanced S-glass/PP warp and weft yarns.

To investigate and compare the microstructure and fibre waviness in the non-crimp and woven fabric laminates, test specimens are cut with a precision cutter and then coated with a thin conductive layer and then examined using scanning electron microscopy (Philips model XL 30 FEG). The fibre architecture and microstructures produced in S-glass UD, S-glass/PP UD, S-glass/PP quasi-UD and Sglass/PP $5 \mathrm{H}$ satin laminates are shown in Fig. 2. As can be seen in Figs. $2 \mathrm{a} \& 2 \mathrm{~b}$, the $0^{\circ}$ and $90^{\circ}$ laminae in the S-glass UD and S-glass/PP UD laminates indicate that the fibre waviness is negligible. Moreover, Figs. $2 a \& 2 b$ show that the S-glass UD lamina has matrix-rich regions between the S-glass yarns whereas the S-glass/PP UD has better fibre distribution reducing the size of inter-yarn matrix-rich regions because of the intra-yarn PP fibres. The thickness of the S-glass/PP UD lamina is however marginally higher than that of the S-glass UD lamina as the PP fibres have a diameter of $\sim 24 \mu \mathrm{m}$ (more than twice the diameter of the S-glass fibres, i.e. $9 \mu \mathrm{m}$ ). In addition, the micrographs of S-glass/PP quasi-UD and S-glass/PP 5H satin laminates shown in Figs. 2c \& $2 \mathrm{~d}$ indicate that the fibre waviness is significantly reduced in S-glass/PP quasi-UD laminates because of the thin S-glass weft yarns. From the micrographs, as shown in Figs. $2 c \& 2 d$, it is also noticed that the intra-yarn matrix-rich area is reduced in the S-glass/PP quasi-UD laminates compared to the S-glass/PP 5H stain laminates.

The laminate properties, i.e. fibre volume fractions, thickness, density and void content, are measured according to BS EN ISO 1183-1 and BS EN ISO 1172 standards and given in Table 3. As can be seen, the S-glass fibre volume fraction is $\sim 28-30 \%$ and the PP fibre volume fraction is $\sim 19-22 \%$ in the hybrid laminates. The S-glass UD laminate thickness (i.e. $\sim 3.15 \mathrm{~mm}$ ) is considerably lower that that of the hybrid laminates; while the thickness of the S-glass/PP quasi-UD is higher that that of the S-glass/PP 
UD and S-glass/PP 5H satin laminates. Furthermore, as the density of the PP fibres $\left(\sim 0.9 \mathrm{~g} / \mathrm{cm}^{2}\right)$ is lower than the S-glass fibres $\left(\sim 2.45 \mathrm{~g} / \mathrm{cm}^{2}\right)$, the density of the S-glass UD laminates is observed to be considerly higher $(\sim 15 \%)$.

Table 3: The laminate properties: thickness, fibre volume fractions, density and void content $\left(v_{f S}\right.$ and $v_{f P}$ are the fibre volume fractions for $S$-glass and $P P$, respectively).

\begin{tabular}{llllll}
\hline Laminate type & $\begin{array}{l}\text { S-glass } \\
\text { fibre volume } \\
\text { fraction, } \\
\left(\boldsymbol{v}_{\boldsymbol{f} s}\right)\end{array}$ & $\begin{array}{l}\text { PP } \\
\text { fibre volume } \\
\text { fraction, } \\
\left(\boldsymbol{v}_{\boldsymbol{f} P}\right)\end{array}$ & $\begin{array}{l}\text { Laminate } \\
\text { thickness, } \\
(\mathbf{m m})\end{array}$ & $\begin{array}{l}\text { Density, } \\
\left(\mathbf{g} / \mathbf{c m}^{3}\right)\end{array}$ & $\begin{array}{l}\text { Void } \\
\text { fraction }\end{array}$ \\
\hline S-glass UD & $0.46 \pm 0.07$ & 0.0 & $3.1 \pm 0.1$ & 1.76 & 0.014 \\
S-glass/PP UD & $0.28 \pm 0.02$ & $0.20 \pm 0.02$ & $4.2 \pm 0.1$ & 1.48 & 0.010 \\
S-glass/PP quasi-UD & $0.30 \pm 0.03$ & $0.19 \pm 0.02$ & $4.7 \pm 0.1$ & 1.45 & 0.026 \\
S-glass/PP 5H satin & $0.30 \pm 0.01$ & $0.22 \pm 0.01$ & $4.5 \pm 0.1$ & 1.49 & 0.016 \\
\hline
\end{tabular}

\section{Experimental Characterisation}

\subsection{In-plane Mechanical Properties}

\subsubsection{Tensile Strength}

To characterise the laminate in-plane tensile properties, standard test specimens are cut from the laminate panels manufactured with a diamond cutter, measuring $250 \mathrm{~mm} \times 25 \mathrm{~mm}$ in accordance with ASTM D3039M 2008. For each laminate type, five specimens are tested. For the S-glass/PP 5H satin laminates, tensile tests are conducted for both warp and weft directions. Tensile tests are conducted at room temperature using an Instron 5982 testing machine at a crosshead displacement rate of 2.0 $\mathrm{mm} / \mathrm{min}$. The strains are measured along the specimen length and width directions using a video extensometer monitoring a gauge length of $50 \mathrm{~mm}$.

Table 4: The in-plane laminate tensile properties ( $\sigma_{u t}^{L}$ is the laminate tensile failure stress and $E_{t}^{L}$ is the laminate tensile modulus, and $v_{f S}$ and $v_{f P}$ are the fibre volume fractions for $S$-glass and $P P$, respectively).

\begin{tabular}{|c|c|c|c|c|c|c|}
\hline Laminate type & $\begin{array}{l}\sigma_{u t}^{L} \\
(\mathrm{MPa})\end{array}$ & $\begin{array}{l}E_{t}^{L} \\
(\mathrm{GPa})\end{array}$ & $\begin{array}{l}\sigma_{u t}^{L} / v_{f S} \\
(\mathrm{MPa})\end{array}$ & $\begin{array}{l}E_{t}^{L} / v_{f S} \\
(\mathrm{GPa})\end{array}$ & $\begin{array}{l}\sigma_{u t}^{L} / v_{f S} \\
\text { change } \\
(\%)\end{array}$ & $\begin{array}{l}E_{t}^{L} / v_{f S} \\
\text { change } \\
(\%)\end{array}$ \\
\hline S-glass UD & $617 \pm 44$ & $23.6 \pm 4.4$ & $1341 \pm 95$ & $51.3 \pm 9.5$ & - & - \\
\hline S-glass/PP UD & $379 \pm 13$ & $15.0 \pm 1.0$ & $1354 \pm 46$ & $53.5 \pm 3.6$ & +0.9 & +4.3 \\
\hline S-glass/PP quasi-UD & $390 \pm 18$ & $16.3 \pm 0.8$ & $1300 \pm 60$ & $54.3 \pm 2.6$ & -3.0 & +5.8 \\
\hline S-glass/PP 5H satin (warp) & $242 \pm 3$ & $9.2 \pm 1.1$ & $806 \pm 10$ & $30.6 \pm 3.6$ & -39.9 & -40.3 \\
\hline S-glass/PP 5H satin (weft) & $275 \pm 6$ & $10.4 \pm 0.4$ & $916 \pm 20$ & $34.6 \pm 1.3$ & -31.7 & -32.5 \\
\hline
\end{tabular}

The in-plane laminate tensile properties are compared in Table 4. As the fibre volume fractions in the laminates are not constant, the laminate tensile strength $\left(\sigma_{u t}^{L}\right)$ and modulus $\left(E_{t}^{L}\right)$ are normalised using the S-glass fibre volume fraction $\left(v_{f S}\right)$-assuming that the role of the PP fibres is predominantly to modify the matrix properties and introduce conducive failure mechanisms at a yarn-level. Comparing the normalised laminate tensile strengths $\left(\sigma_{u t}^{L} / v_{f s}\right)$, it can be seen from Table 4 that the normalised tensile strength of the S-glass UD laminates is close $(\sim 1 \%)$ to that of the S-glass/PP UD laminates. However, for the S-glass/PP stain laminates, a reduction of $\sim 40 \%$ in the warp direction (and $\sim 32 \%$ in 
the weft direction) is measured, which is significantly lower than that of the S-glass UD laminates. In contrast, for the S-glass/PP quasi-UD laminates, the reduction in the normalised tensile strength is only $\sim 3 \%$. Similarly, comparing the normalised in-plane laminate tensile modulus values $\left(E_{t}^{L} / v_{f s}\right)$, the normalised tensile modulus of the S-glass/PP UD laminates is observed to be marginally higher ( 4\%) to that of the S-glass UD laminates. For the S-glass/PP stain laminates, a reduction of $\sim 40 \%$ in the warp direction (and $\sim 32 \%$ in the weft direction) is measured, which is significantly lower than that of the S-glass UD laminates. In the case of the S-glass/PP quasi-UD laminates, the normalised tensile modulus is observed to be marginally higher $(\sim 6 \%)$. While these comparisons are made by using the Sglass fibre volume faction, it is worth noting that parameters such as fibre waviness, yarn crimp, laminate thickness and layup could affect the laminate tensile strength and modulus, which might be a reason for the marginally higher tensile modulus observed in the S-glass/PP UD and S-glass/PP quasiUD laminates. Based on the variation in the normalised tensile strength and modulus in Table 4, it can be seen that the in-plane tensile properties of the S-glass/PP satin laminates can be significantly improved by reducing yarn crimp via quasi-UD weaves.

\subsubsection{Compressive Strength}

The in-plane compressive properties are measured for each laminate type. The compressive tests are conducted, with a specimen size of $89 \mathrm{~mm} \times 55 \mathrm{~mm}$, at room temperature using an Instron 5989 test machine at $0.5 \mathrm{~mm} / \mathrm{min}$ crosshead displacement rate and with a load cell capacity of $300 \mathrm{kN}$. The specimen edges are clamped to a supporting fixture, which is a modified Boeing test fixture, to prevent buckling under compression. The in-plane laminate compressive properties are given in Table 5, where the laminate compressive strength $\left(\sigma_{u c}^{L}\right)$ and modulus $\left(E_{c}^{L}\right)$ are normalised using the S-glass fibre volume fraction $\left(v_{f S}\right)$. It is seen that the normalised compressive strength $\left(\sigma_{u c}^{L} / v_{f S}\right)$ of the S-glass/PP UD laminates is considerably lower $(\sim 37 \%)$ than that of the S-glass UD laminates. For the S-glass/PP stain laminates, a reduction of $\sim 61 \%$ in the warp direction is measured, which is significantly lower than that of the S-glass UD laminates. On the other hand, for the S-glass/PP quasi-UD laminates, the reduction in the normalised tensile strength is only $\sim 11 \%$. Similarly, it is seen that the normalised compressive modulus values $\left(E_{c}^{L} / v_{f S}\right)$ of the S-glass/PP UD laminates is marginally lower $(\sim 1.5 \%)$ to that of the Sglass UD laminates. For the S-glass/PP stain laminates, a reduction of $\sim 47 \%$ in the warp direction is measured, which is again significantly lower than that of the S-glass UD laminates. However, in the case of the S-glass/PP quasi-UD laminates, the normalised tensile modulus is observed to be marginally higher $(\sim 2.5 \%)$. Although these comparisons are made by using the S-glass fibre volume faction, it is again important to note that parameters such as microstructure, fibre waviness, yarn crimp, matrix properties, laminate thickness and layup could affect the laminate compressive strength and modulus. Similar to the in-plane tensile properties, considering the variation in the normalised compressive strength and modulus observed in Table 5, it can also be seen that the in-plane compressive properties of the S-glass/PP stain laminates can be significantly improved by reducing yarn crimp via quasi-UD weaves.

Table 5: The in-plane laminate compressive properties ( $\sigma_{u c}^{L}$ is the laminate compressive failure stress and $E_{c}^{L}$ is the laminate tensile modulus, and $v_{f S}$ and $v_{f P}$ are the fibre volume fractions for $S$-glass and PP, respectively).

\begin{tabular}{|c|c|c|c|c|c|c|}
\hline Laminate type & $\begin{array}{l}\sigma_{u c}^{L} \\
(\mathrm{MPa})\end{array}$ & $\begin{array}{l}E_{c}^{L} \\
(\mathrm{GPa})\end{array}$ & $\begin{array}{l}\sigma_{u c}^{L} / v_{f S} \\
(\mathrm{MPa})\end{array}$ & $\begin{array}{l}E_{c}^{L} / v_{f S} \\
(\mathrm{GPa})\end{array}$ & $\begin{array}{l}\sigma_{u c}^{L} / v_{f S} \\
\text { change } \\
(\%)\end{array}$ & $\begin{array}{l}E_{c}^{L} / v_{f S} \\
\text { change } \\
(\%)\end{array}$ \\
\hline S-glass UD & $277 \pm 16$ & $18.7 \pm 0.4$ & $602 \pm 34$ & $40.6 \pm 0.8$ & - & - \\
\hline S-glass/PP UD & $106 \pm 15$ & $11.2 \pm 0.4$ & $378 \pm 53$ & $40.0 \pm 1.4$ & -37.2 & -1.4 \\
\hline S-glass/PP quasi-UD & $161 \pm 6$ & $12.5 \pm 0.8$ & $537 \pm 20$ & $41.6 \pm 2.6$ & -10.8 & +2.4 \\
\hline S-glass/PP 5H satin (warp) & $71 \pm 9$ & $6.5 \pm 0.7$ & $236 \pm 30$ & $21.6 \pm 2.3$ & -60.8 & -46.8 \\
\hline
\end{tabular}



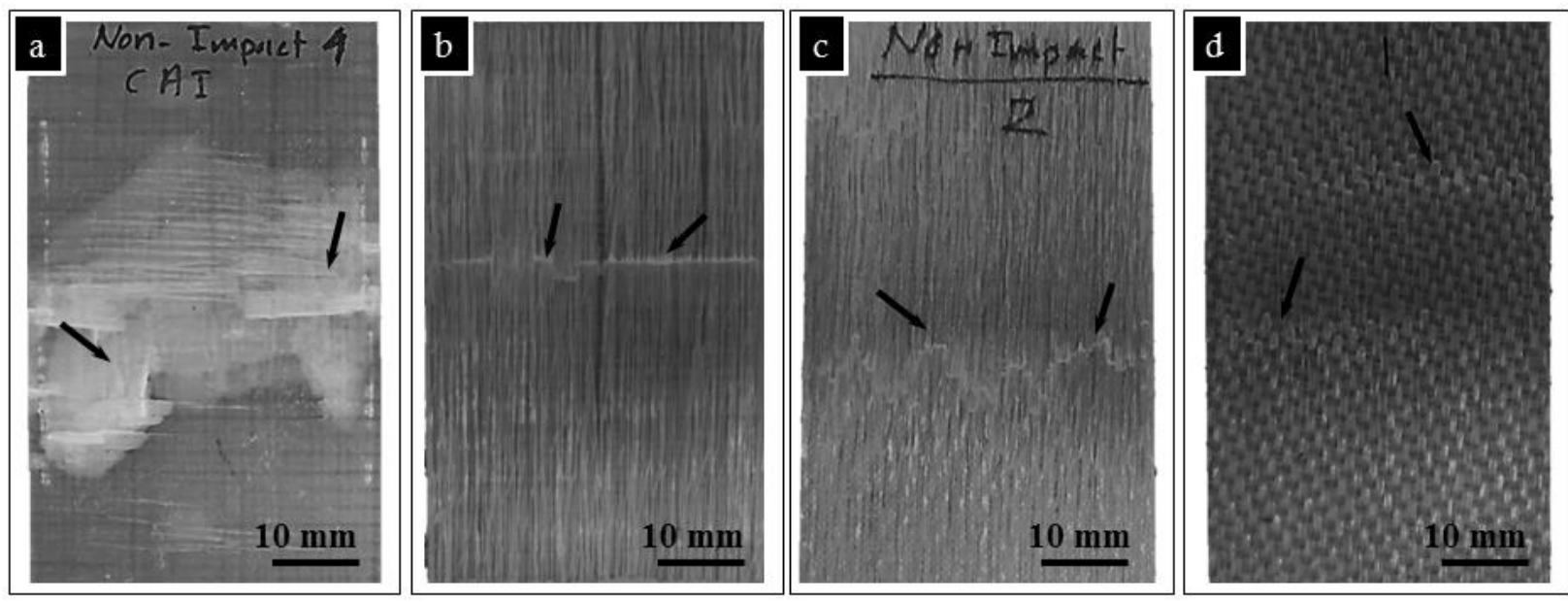

Figure 4: The near-surface compressive damage in: (a) S-glass UD, (b) S-glass/PP UD, (c) S-glass/PP quasi-UD, and (d) S-glass/PP $5 H$ satin laminates.

The near-surface visible damage modes observed in the compressive tests are shown Fig. 4. The visible surface damage in the S-glass UD laminates indicate delamination, fibre breakage and matrix cracking (see Fig. 4a) whereas fibre breakage and matrix cracking without delamination is observed in the Sglass/PP UD, S-glass/PP quasi-UD and S-glass/PP satin laminates (see Figs. 4b, 4c \& 4d). As the images shown in Fig. 4 cannot provide an insight into the sub-surface macro- and micro-failure modes, the damaged specimens are sectioned and studied using scanning electron microscopy.

The SEM micrographs obtained from the sectioned specimens are shown in Fig. 5 for the S-glass UD, S-glass/PP UD, S-glass/PP quasi-UD and S-glass/PP satin lamainates. In Fig. 5a the compressive failure modes in the S-glass UD lamiantes are shown. The micrographs clearly indicate multile delaminations, marix cracking, fibre breakage, kink bands and transverse shear fracture. The comressive tests conducted have shown a catastrophic failure indicating a brittle response. As multiple delaminations can be seen in Fig. 5a, this is in agreement with the brittle failure behaviour observed. In contrast, the compressive failure modes in the S-glass/PP UD laminates (see Fig. 5b) are fibre breakage, kink bands, intra-yarn PP fibre-matrix debonding and transvere shear fracture. The failure observed is along a shear plane without noticable delamination, which is also in agreement with the brittle failure observed in the comressive tests. This indicates that the PP fibres introduced at the yarn-level have a clear affect on the compressive failure modes, which could be attributed to the variation in laminate thickness and microstructure observed (i.e. S-glass and PP fibre-rich regions, and better fibre distribution with reduced matrix-rich regions) in Fig. $2 \mathrm{~b}$ compared to Fig. $2 \mathrm{a}$. In addition, the compressive failure modes in the S-glass/PP quasi-UD laminates are shown in Fig. 5c. Fibre breakage, marix cracking, kink bands and transverse shear fracture can be seen with delamination being significantly suppressed similar to that in the S-glass/PP UD laminates. As can be seen in Fig. 5c, fibre breakage and intra-yarn cracking near the thin S-glass weft yarns suggest that the crimped regions of these weft yarns can introduce damage in compression. Unlike the failure observed in the S-glass/PP UD lamainates, the failure is not along a sigle shear plane, suggesting that the damage initiated in multiple regions before failure. Furthermore, the compressive failure modes in the S-glass/PP satin laminates are shown in Fig. 5d. Fibre breakage, marix cracking and transverse shear fracture are observed without delamination similar to that in the S-glass/PP UD and quasi-UD laminates. It is important to note that intra-yarn PP fibre-matrix debonding, without noticeable intra-yarn S-glass fibrematrix debonding, is observed in the S-glass/PP stain laminates. As yarn crimp introduces local stresses when subject to in-plane compression, it appears that intra-yarn damage via PP fibre-matrix debonding is initiated. Moreover, the high normalised compressive strength of the S-glass/PP quasi-UD laminates (537 $\mathrm{MPa}$ and $\sim 1.5 \%$ crimp in warp yarns) in comparison to that of the S-glass/PP satin laminates (236 $\mathrm{MPa}$ and $\sim 4 \%$ crimp in warp yarns) also suggests that the intra-yarn damage introduced via PP fibrematrix debonding has a significant effect on the compressive failure of these hybrid laminates, and that the compressive strength can be improved by reducing yarn crimp. 

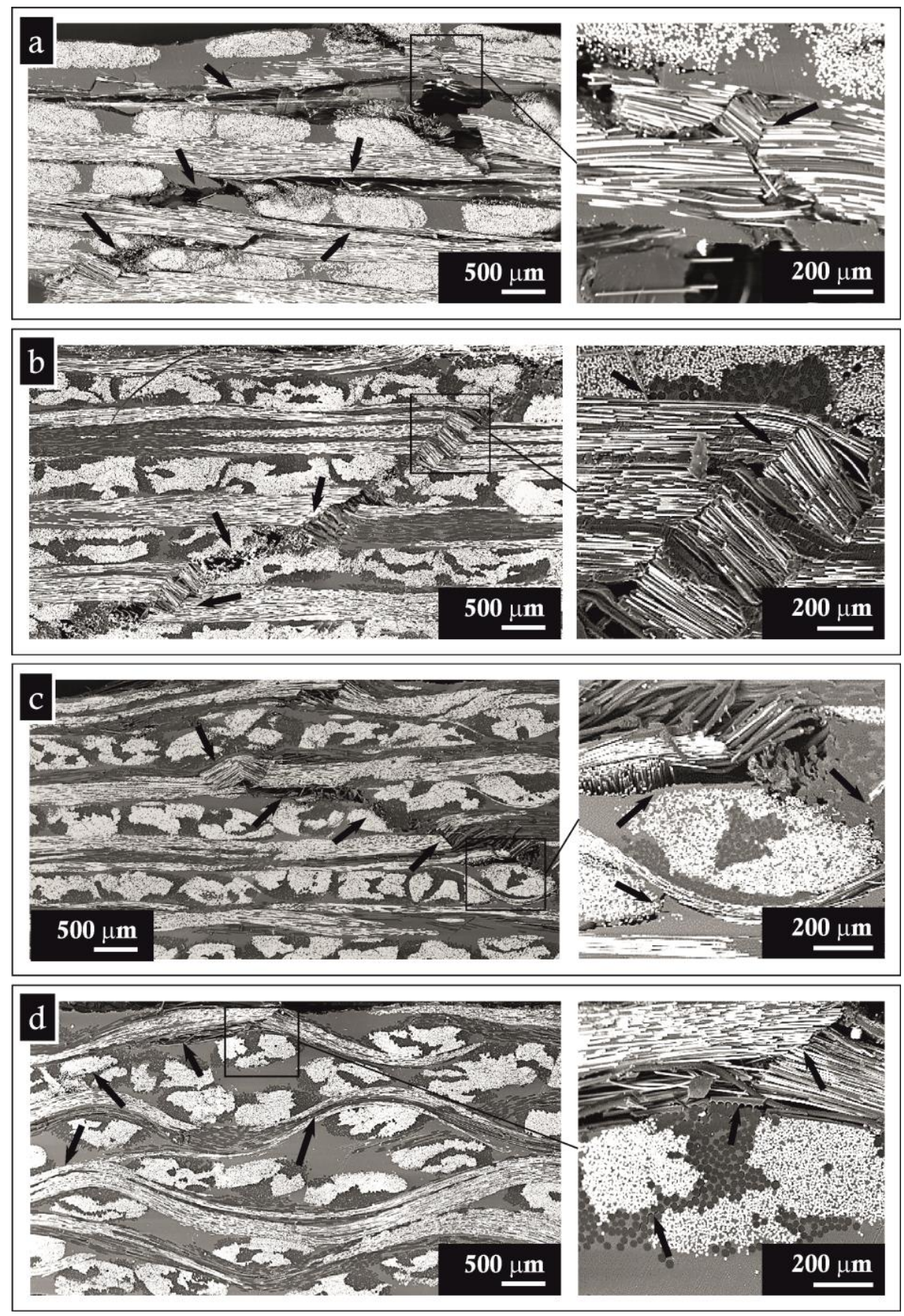

Figure 5: The sub-surface damage modes in compression: (a) S-glass UD,(b) $S$-glass/PP UD, (c) $S$-glass/PP quasi-UD, and (d) S-glass/PP $5 H$ satin laminates.

\subsection{Low velocity Impact Response}

The impact behaviour of the laminates is investigated for low velocity impact loading. A drop-weight impact test machine (CEAST 9350) is used for the low velocity impact tests. The mass and diameter of the hemispherical impactor tip used are $5.03 \mathrm{~kg}$ and $20 \mathrm{~mm}$, respectively. The impact tests are conducted at four impact energy levels (i.e. 15, 25, 35 and 50 Joules) by varying the height of the impactor (i.e. 304, 506, 710 and $1012 \mathrm{~mm}$, respectively) — with impactor velocities 2.42, 3.13, 3.70 and $4.43 \mathrm{~m} / \mathrm{s}$, respectively, at the moment of impact. Following the Pichard and Hogg protocol [35] for impact and compression-after-impact tests, the specimens (i.e. $55 \mathrm{~mm} \times 89 \mathrm{~mm}$ ) are sandwiched between two metal plates with a circular opening of $40 \mathrm{~mm}$ and the plates are clamped. The test machine is equipped with a data acquisition system, a piezoelectric transducer and an anti-rebound system. The contact force-time data is recorded with a sampling frequency of $500 \mathrm{kHz}$ during impact. The velocity, displacement and absorbed energy histories are calculated from the contact force-time 
history by numerical integration. For each specimen type, drop-weight impact tests are conducted at 15 , 25,35 and $50 \mathrm{~J}$ energy levels - with at least 4 specimens for each energy level. The dent depth at the point of impact is measured using a digital depth gauge on the impacted surface of the specimens. The specimens are then non-destructively assessed using C-scans-with a Midas NDT water-jet throughtransmission ultrasonic scanner with a $1 \mathrm{MHz}$ probe at $200 \mathrm{~mm} / \mathrm{s}$ speed - to detect and evaluate the impact induced damage.
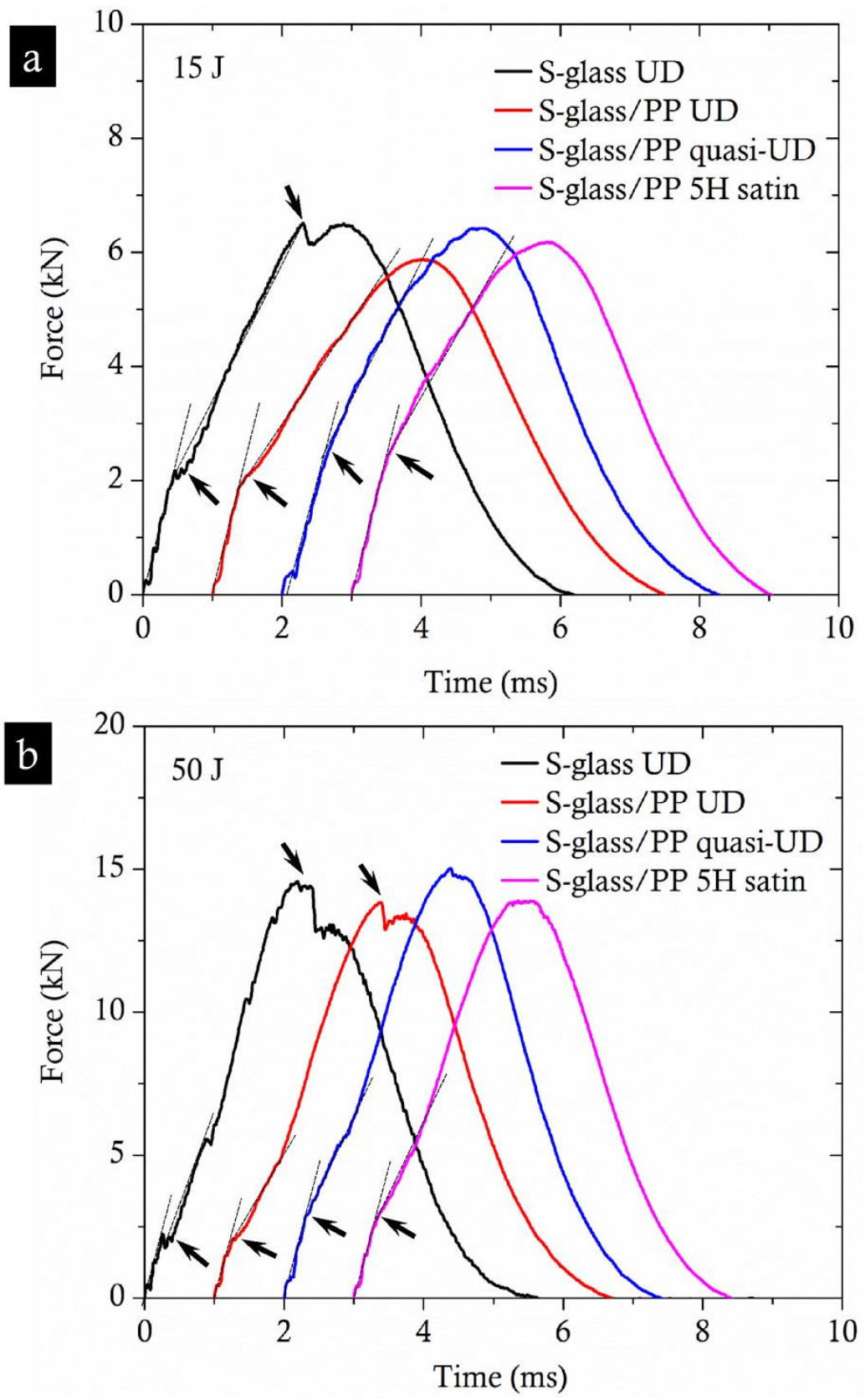

Figure 6: Comparison of the force-time curves for: (a) $15 \mathrm{~J}$ and (b) $50 \mathrm{~J}$ impact energy levels.

The force-time and force-displacement curves obtained for the drop-weight impact tests are shown in Figs. 6-7 as minor and major damage events during impact can be identified from such plots. In Fig. 6, the force-time curves from the S-glass UD, S-glass/PP UD, S-glass/PP quasi-UD and S-glass/PP satin laminates are compared for two impact energy levels (i.e. 15 and $50 \mathrm{~J}$ ). Note that the force-time curves for the four laminate types are presented with a $1 \mathrm{~ms}$ offset for clarity. For a $15 \mathrm{~J}$ impact (see Fig. 6a), it can be seen that a distinct knee point with a considerable change in the initial slope, which can indicate damage initiation (e.g. matrix cracking), can be identified for all the specimens when the contact force is between $2-2.5 \mathrm{kN}$. The change in the initial slope in the S-glass/PP UD is considerably higher compared to the other laminates. The load levels corresponding to the knee points for the S-glass UD 
and S-glass/PP UD can be seen to be marginally lower than those for the S-glass/PP quasi-UD and Sglass/PP satin laminates. In addition, the force-time curves from the S-glass UD laminates show a sudden load drop (at a load of $6.6 \mathrm{kN}$ ) indicating a major damage event which is unstable such as delamination growth and fibre breakage. Similarly, for a $50 \mathrm{~J}$ impact (see Fig. 6b), the knee points can again be identified for all the specimens when the contact force is between $2-3 \mathrm{kN}$. The force-time curves show a sudden load drop at a load of $14.6 \mathrm{kN}$ and $13.8 \mathrm{kN}$ for the S-glass UD and S-glass/PP laminates, respectively. But such sudden load drops are not seen for the S-glass/PP quasi-UD and Sglass/PP satin laminates, which manifests that the damage modes in these two woven laminates are stable and different compared to those in the S-glass and S-glass/PP UD laminates.
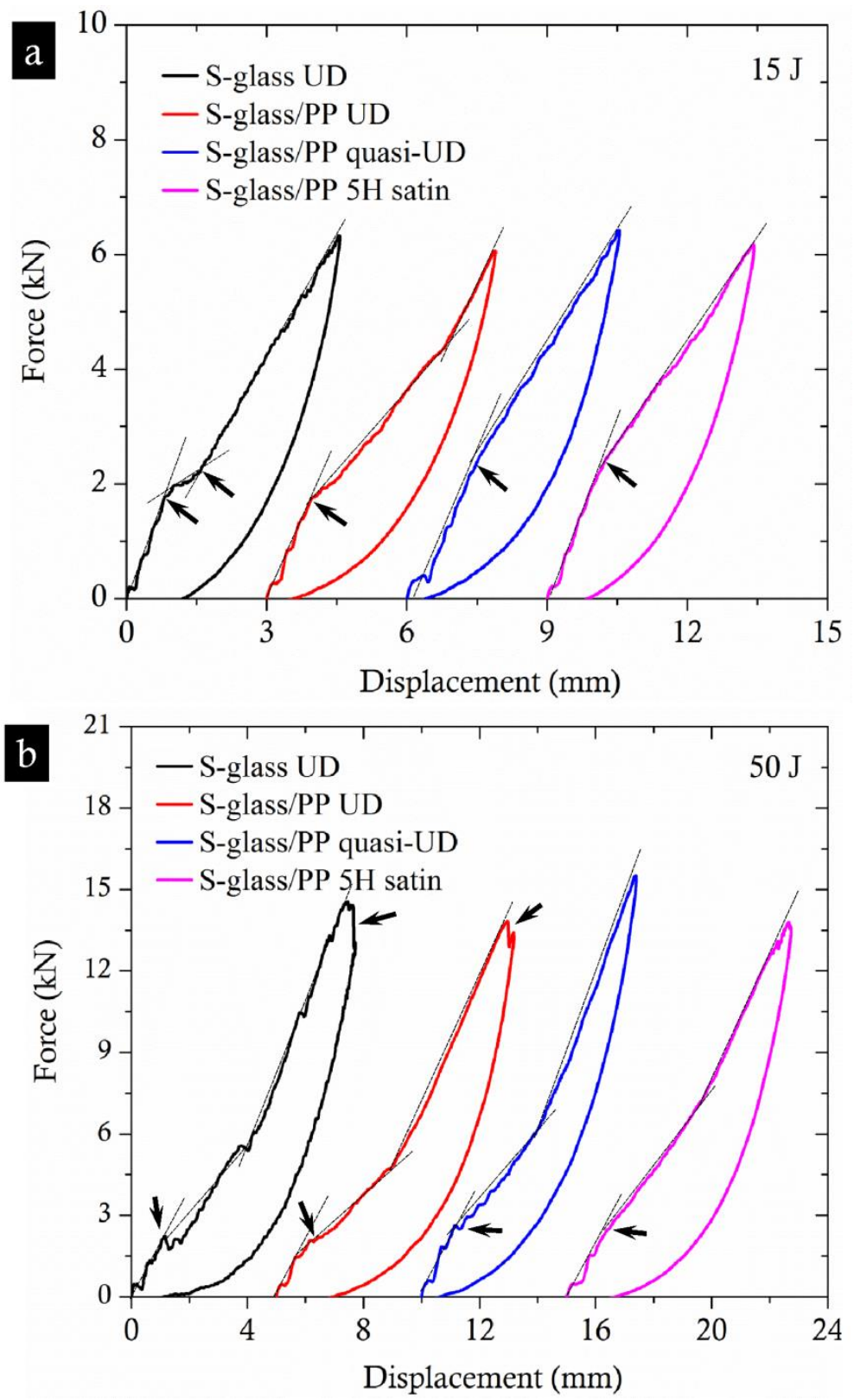

Figure 7: Force-displacement curves at: (a) $15 \mathrm{~J}$ and (b) $50 \mathrm{~J}$ impact energy levels.

In Fig. 7, the force-displacement curves obtained from the S-glass UD, S-glass/PP UD, S-glass/PP quasi-UD and S-glass/PP satin laminates are compared for 15 and $50 \mathrm{~J}$ impact energies. Note that the force-time curves for the four laminate types are presented with an offset for clarity $(3 \mathrm{~mm}$ for Fig. $7 \mathrm{a}$ and $5 \mathrm{~mm}$ for Fig. 7b). For a $15 \mathrm{~J}$ impact (see Fig. 7a), the difference in the loading and unloading paths show that some of the impact energy is absorbed inducing damage. Moreover, the unloading paths clearly show that the impactor did not penetrate the laminates. Corresponding to the force-time curves, the knee points can also be seen in all the specimens when the contact force is between $2-2.5 \mathrm{kN}$. As the 
change in the initial stiffness in the S-glass/PP UD is considerably higher, it suggests that the Sglass/PP laminate stiffness is sensitive to the damage modes introduced. In contrast, the stiffness of the $\mathrm{S}$-glass/PP quasi-UD and S-glass/PP satin laminates appears to be less sensitive to the initial damage modes introduced. Furthermore, the force-displacement curves presented in Fig. $7 \mathrm{~b}$ for a $50 \mathrm{~J}$ impact show a sudden load drop at the peak contact force indicating a delamination threshold or unstable damage growth for the S-glass UD and S-glass/PP UD laminates.

After impact testing, the specimens are examined using C-scans with the aim of establishing a correlation between the impact energy and damage area. For the four laminate types tested, the damage area versus impact energy plots are compared and shown in Fig. 8. It can be observed that the damaged area, based on the detected damage modes via C-scans, increased with increasing impact energies for all the specimens. In addition, the damage area in the S-glass UD laminates is larger than that in the other three laminate types, indicating that the presence of intra-yarn PP fibes has reduced the damage area. The effect of yarn crimp can also be seen in Fig. 8. The damage area in the S-glass/PP satin lamiantes is considerably smaller than that in the S-glass/PP quasi-UD laminates. With a high degree of crimp in warp and weft yarns, the damage introduced is localised in the S-glass/PP satin laminates as the crimped yarns could hinder the extension of the intra-yarn cracks and suppress the growth of matrix cracking and delamination. It is also clear that the damage area in the S-glass/PP satin laminates is smaller than that is the other three laminate types. However, it is impartant to notice that the damage area in the S-glass/PP quasi-UD laminates (with crimp) is marginally greater than that in the S-glass/PP UD laminates (without crimp). This suggests that the thin weft yarns have introduced stress concentration and local damage affecting the impact damage area.

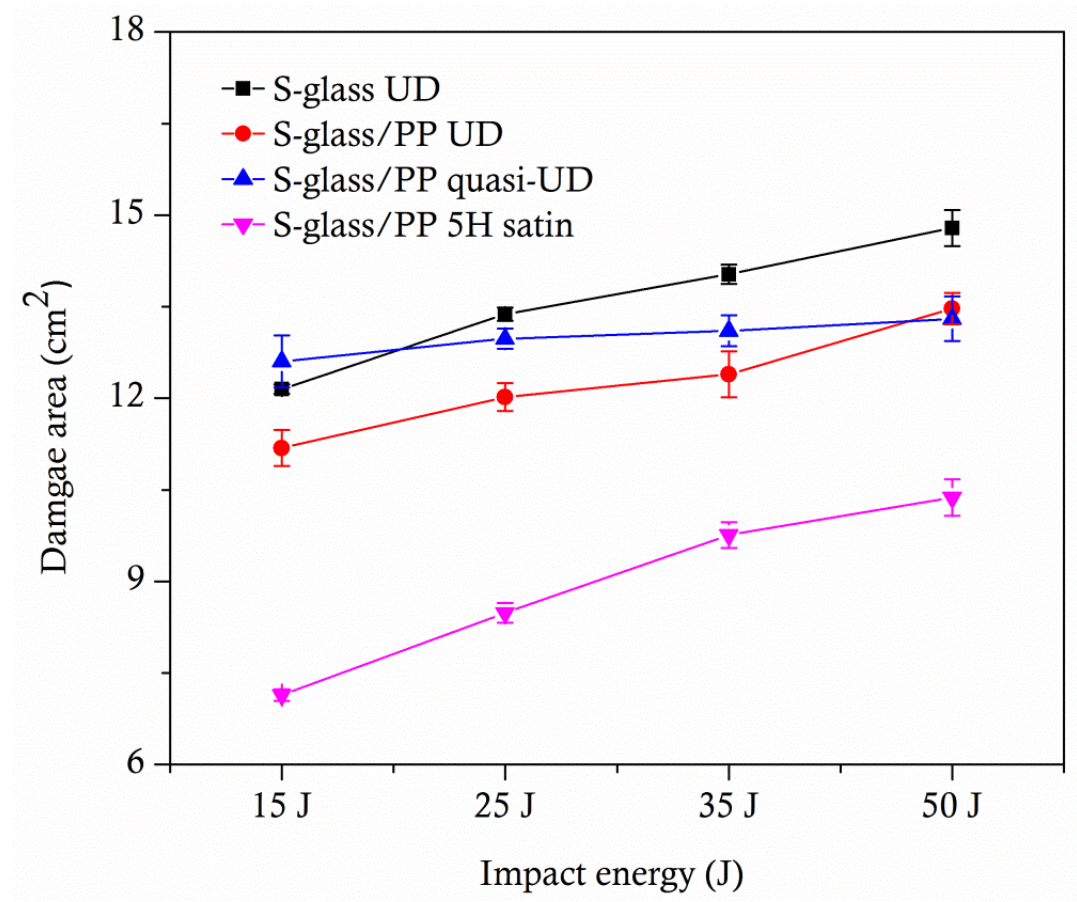

Figure 8: Comparison of the impact damage area with varying impact energies in the S-glass UD, S-glass/PP UD, $S$-glass/PP quasi-UD and S-glass/PP satin laminates.

The force-time and force-displacement curves in Figs. 6-7 show that the impactor has neither a perfectly elastic rebound nor a fully penetration through the laminate, and that the kinetic energy of the impactor has partly absorbed via sub-surface damage modes. It is worth noting that the peak displacements include both the deflection of the laminate and the local indentation at the point of contact during impact. To characterise the laminate response near the point of contact with the impactor, the dent depth is measured using a digital gauge immediately after the impact and then again after 24 hours. The measured dent depths for the laminates at each energy level are compared and shown in Fig. 9. The dent depth in the S-glass/PP quasi-UD is considerably smaller than that in the S-glass UD, S-glass/PP UD and S-glass/PP satin laminates. Moreover, the dent depth recovery in the S-glass/PP quasi-UD 
laminates is negligible; whereas a significant amount is recovered in the S-glass UD and S-glass/PP UD laminates. This suggests that the damage modes introduced during impact allowed the local deformation to recover considerably in the non-woven laminates, indicating relatively large sub-surface damage region such as delamination. In contrast, the S-glass/PP satin laminate is observed to have relatively low dent depth recovery, suggesting localised sub-surface damage modes.

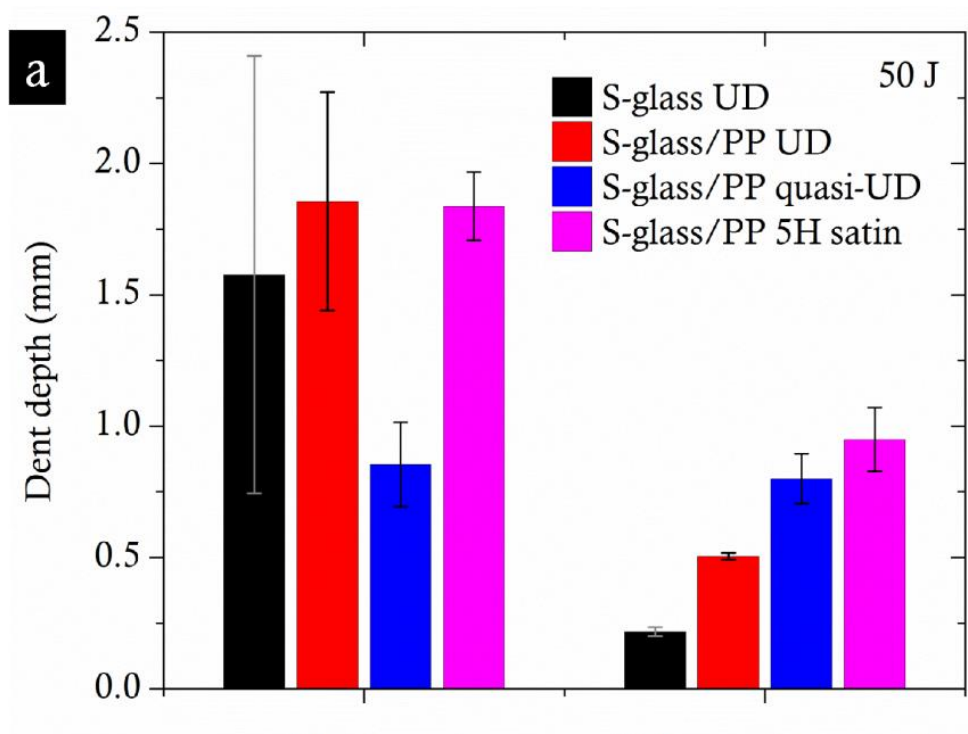

After impact $\quad 24$ hours after impact

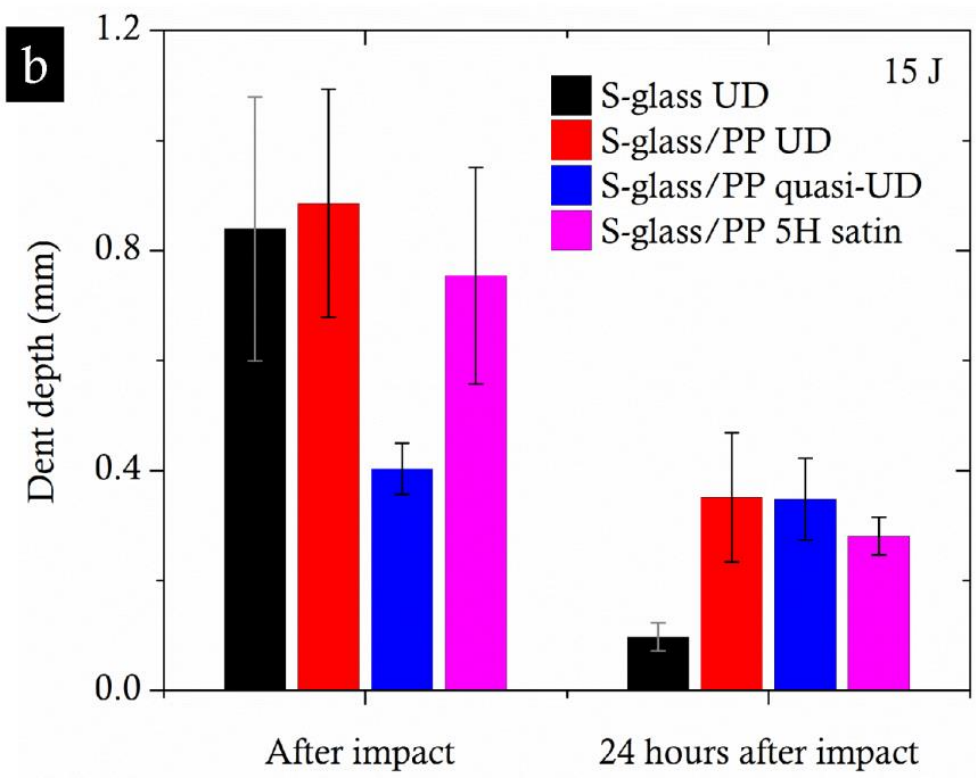

Figure 9: The dent depth recovery in the S-glass UD, S-glass/PP UD, S-glass/PP quasi-UD and S-glass/PP satin laminates: (a) $50 \mathrm{~J}$ and (b) $15 \mathrm{~J}$ impact energies.

The damaged S-glass and S-glass/PP laminates with an impact energy of $35 \mathrm{~J}$ are investigated using scanning electron microscopy to identify the effect of yarn hybridisation and fibre architecture on failure mechanisms. The sub-surface damage regions beneath the impact point are studied by carefully sectioning the damaged specimens with a precision cutter. In Fig. 10, the SEM micrographs are presented. The response of the S-glass UD laminate is shown in Fig. 10a, which shows that the failure is dominated by delamination and intra-laminar matrix shear cracks. In comparison, the failure modes in the S-glass/PP UD laminates (see Fig. 10b) show that transverse micro-cracks are introduced within hybrid yarns, especially via PP fibre-epoxy debonding, and delamination is significantly reduced. This suggests that the yarn-level hybridisation used by incorporating the commodity PP fibres, for commingling and core-wrapping processes, with poor fibre-matrix interface properties, introduced intra-yarn energy dissipation mechanisms as a result of multiple transverse micro-cracks within the 
hybrid yarns - thus reducing delamination. In addition, the failure modes observed in the S-glass/PP quasi-UD and S-glass/PP satin laminates are shown in Figs. 10c \& 10d, respectively. In the S-glass quasi-UD laminate, delamination and intra-laminar cracks are observed. The damge in and around the crimpred reggion of the thin weft yarns can be clearly seen in Fig. 11c, confirming that the S-glass weft used in the quais-UD weave can influence the damage modes. In the S-glass/PP satin laminates (see Fig. 11d), intra-lamina cracks in the form of intra-yarn matrix cracking, PP fibre-epoxy debonding and inter-yarn (resin-rich) regions are predominantly seen together with delamination (crack growth along crimped yarns). The variation in the damage modes observed in Figs. 11a-d suggests that the nonhybrid and non-crimp architecture in the S-glass UD laminates absorb energy predominantly via delamination, whereas the intra-yarn damage modes introduced using the hybrid and crimp architecture in the S-glass/PP quais-UD and S-glass/PP satin laminates can absord energy and thus significantly reduce delamination.
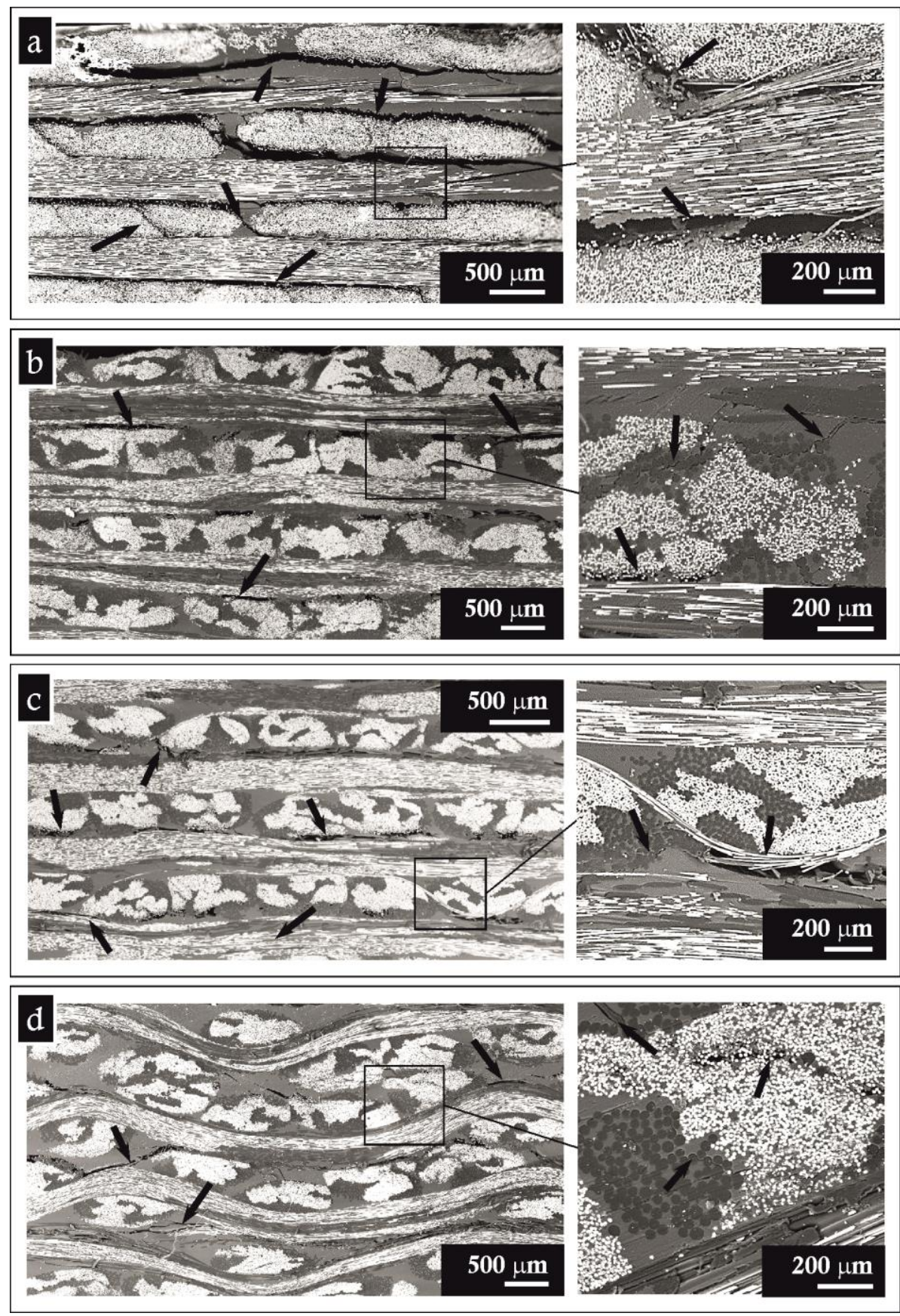

Figure 10: The sub-surface damage modes under transverse impact with $35 \mathrm{~J}$ energy: (a) $S$-glass $U D$,(b) $S$ glass /PP UD, (c) S-glass/PP quasi-UD, and (d) S-glass/PP $5 H$ satin laminates. 


\subsection{Post-impact Compressive Response}

The impact damage tolerance of the S-glass UD, S-glass/PP UD, S-glass/PP quasi-UD and S-glass/PP satin laminates is investigated by measuring post-impact compressive strengths for different impact energy levels. Comparing with the compressive strength of the undamged laminates, the residual compressive strength is used to assess the role of yarn-level hybridisation and yarn crimp of the impact damage tolerance. Similarl to the compressive tests conducted on the undamed specimens, the postimpact compressive tests are performed at room temperature with a constant cross-head displacement of $0.5 \mathrm{~mm} / \mathrm{min}$ and the impact damaged specimen edges are clamped to prevent buckling global buckling. In addition, the tested specimens are carefully sectioned with a precision cutter and the postimpact compressive damage modes are investigated and subsequently compared with the compressive damage modes.
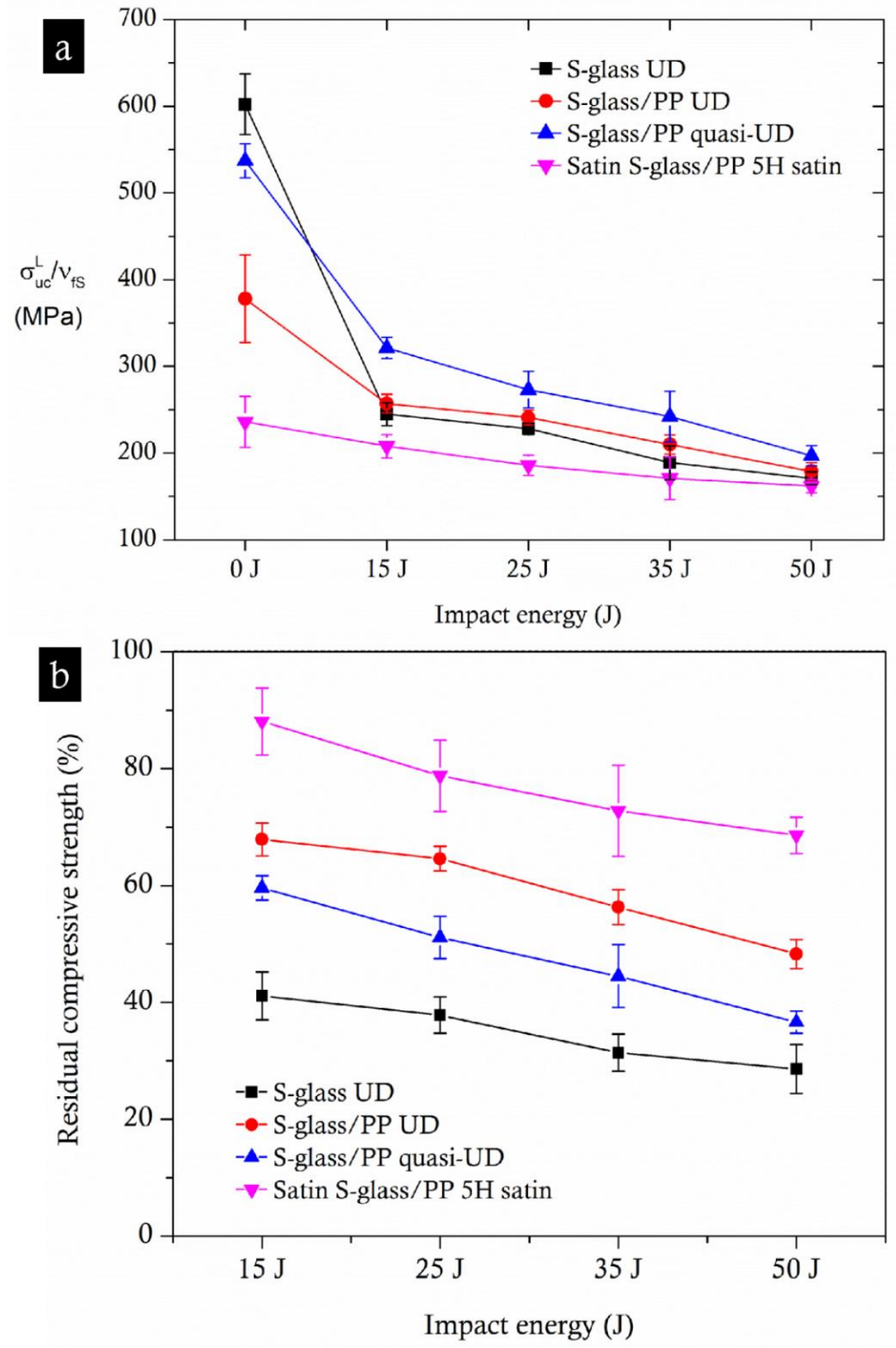

Figure 11: Comparison of the compressive strengths of the S-glass UD, S-glass /PP UD, S-glass/PP quasi-UD and $S$-glass /PP satin laminate: (a) post-impact normalised compressive strengths and (b) residual compressive strengths. 
In Fig. 11a, the compressive strengths measured for the undamaged and impact damaged laminates are presented for different impact enery levels $(0,15,25,35$ and $50 \mathrm{~J})$. Note that the compressive strength is normalised using the S-glass fibre volume fraction for each laminate type $\left(\sigma_{u c}^{L} / v_{f s}\right)$. For the S-glass UD laminates, a reduction of $\sim 71 \%$ in the compressive strength is measured for a $50 \mathrm{~J}$ impact. It is evident from Fig. 11a that the reduction in the post-impact compressive strength is significant $(\sim 59 \%)$ between $0-15 \mathrm{~J}$ as the normalised compressive strength is reduced from $\sim 602 \mathrm{MPa}$ to $\sim 245 \mathrm{MPa}$, and is relatively less significant between $15-50 \mathrm{~J}$. The post-impact compressive strength of the S-glass/PP UD laminates show a considerable reduction with impact damage ( $\sim 52 \%$ reduction for a $50 \mathrm{~J}$ impact). Comparing the undamaged and post-impact compressive strengths of the S-glass UD and S-glass/PP UD laminates, it can be observed that the yarn-level hybridisation can considerably enhance the postimpact compressive strength of the laminates $(\sim 19 \%)$-although the undamaged compressive strength is considerably reduced $(\sim 37 \%)$. In contrast, the S-glass/PP satin laminates show only a reduction of $\sim 28 \%$ in the compressive strength for a $50 \mathrm{~J}$ impact energy, and the curve with a gradually varying slope in Fig. 11a indicates that the impact damage modes are less sensitive to post-impact compression; but the undamaged compressive strength is significatly less compared to that of the S-glass UD laminates $(\sim 60 \%)$. In this regard, it is impartant to notice in Fig. 11a that the undamged compressive strength of the S-glass/PP quasi-UD laminates is significantly higher than that of the S-glass/PP satin laminates and at the same time only marginally lower than that of the S-glass UD laminates. Moreover, the post-impact compressive strength is higher that those of the S-glass UD, S-glass/PP UD and Sglass/PP satin laminates - clealry indicating that the quasi-UD weaves with yarn-level hybridisation can be used to balance both undamaged and post-impact compressive strengths. The possiblity of such a balance is further evident from the residual compressive strengths shown in Fig. 11b, where the Sglass/PP quasi-UD curve is in between the S-glass UD and S-glass/PP satin curves.
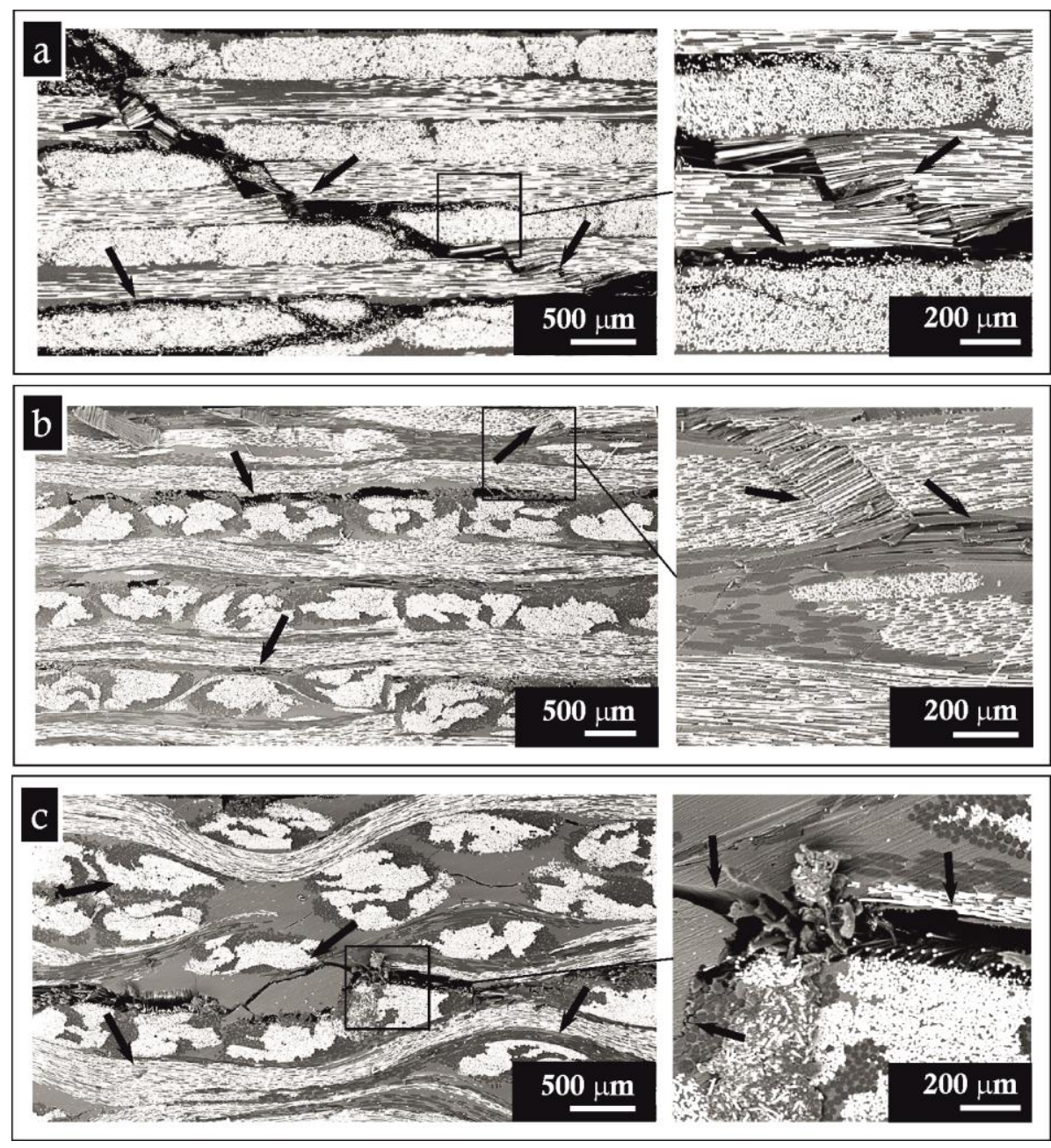

Figure 12: The sub-surface damage modes under post-impact compression with a $35 \mathrm{~J}$ impact: (a) S-glass UD, (b) $S$-glass $/ P P$ quasi-UD, and (c) $S$-glass $/ P P 5 H$ satin laminates. 
The post-impact compression damage modes observed in the S-glass UD, S-glass/PP quasi-UD and Sglass/PP satin laminates are shown in Fig. 12. Note that these laminates are initially subjected to a $35 \mathrm{~J}$ impact to introduce impact damage and subsequently tested to failure in compression. The micrographs of the post-impact damage modes are obtained by sectioning along the length of the specimens (i.e. along the direction of the compressive load applied). In general, the post-impact compression behaviour of impact damaged composite laminates is driven by local and local-global instabilities, which are sensitive to the micro- and macro-damage modes introduced during impact. In Fig. 12a, the postimpact compression damage modes observed in the S-glass UD laminates are shown. A major plane of shear fracture with fibre breakage and kink bands can be seen along with multiple delaminations introduced by the impact load on either side of the fracture plane, which suggests that the post-impact compressive damage modes (see Fig. 12a) are influenced by the presence of the impact damage modes (see Fig. 10a). As expected, the post-impact compression failure seems to have been sensitive to the multiple delaminations introduced during impact. In addition, the post-impact compression damage modes in the S-glass/PP quasi-UD laminates are shown in Fig. 12b. The delamination induced damage is considerably suppressed and that the compressive failure appears to have been driven by kink band formation with some degree of delamination. Comparing Fig. 12b with Fig. 10c, the post-impact compressive damage modes in the S-glass/PP quasi-UD laminates indicate that the impact damage with limited delamination is less sensitive to introducing local-global instabilities in post-impact compression. Furthermore, the damage modes in the S-glass/PP satin quasi-UD laminates are shown in Fig. 12c, where the compressive failure appears to have been influenced by the presence of inter-yarn matrix damage and delamination with irregular planes between warp and weft yarns (see Fig. 10d).
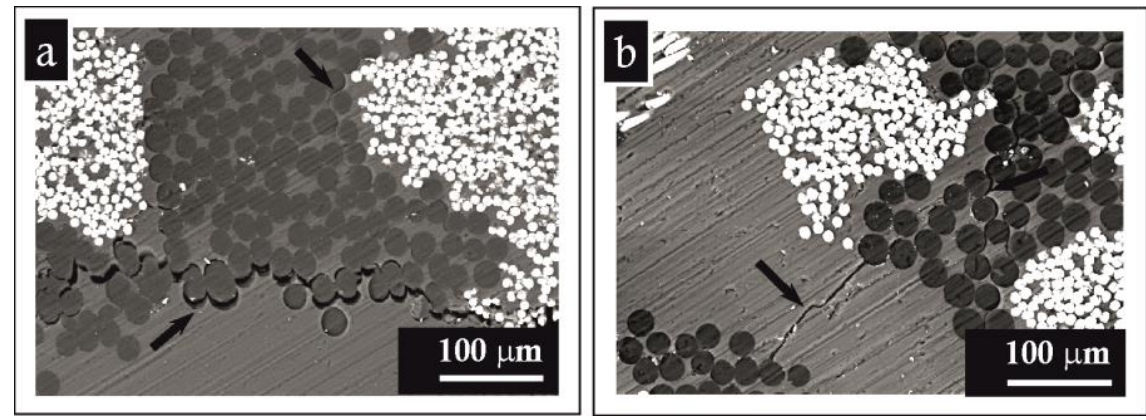

Figure 13: The micro-damage modes in S-glass/PP yarns: (a) PP fibre-epoxy debonding with undamaged S-glass fibre-rich regions, and (b) matrix-cracking in epoxy-rich regions between $P P$ fibre-rich regions.

\section{Discussion}

It is shown that the S-glass/PP quasi-UD laminates, in comparison to the S-glass/PP satin laminates, have provided significantly higher in-plane undamaged tensile and compressive strengths (see Tables. 45), and also introduced benign impact damage modes (see Fig. 10) that offered significantly higher postimpact compressive strengths (see Fig. 11). It can also be seen that, comparing the post-impact compression damage modes in the S-glass/PP quasi-UD laminates with those of the S-glass/PP satin laminates, the fibre architecture and yarn-level hybridisation used in the quasi-UD weaves can be applied to introduce energy absorbing damage modes which are less sensitive to post-impact compressive loading. In general, the micrographs obtained from the compression, impact and postimpact compression damaged laminates clearly show that the low stiffness of PP fibres and poor PP fibre-matrix interface adhesion have influenced the in-plane properties and impact damage tolerance of the four laminate types. It is also clear from the intra-yarn damage modes observed in the S-glass/PP quasi-UD and S-glass/PP satin (see Fig. 13) that the mismatch between the high stiffness and brittle Sglass fibres and the low stiffness and high ductile PP fibres can be used to promote micro-damage via PP fibre-matrix debonding without damaging S-glass fibre-rich regions and also propagate damage connecting PP fibre-rich with epoxy-rich matrix cracking.

The impact and post-impact damage modes in S-glass/PP quasi-UD laminates could potentially be altered for achieving high residual compressive strengths by varying the parameters that define quasiUD weaves (e.g. linear densities of warp and weft yarns, weave patterns, and yarn spacing) and hybrid 
yarns (e.g. fibre volume fractions and distribution). However, to understand the individual or combined effect of such parameters on in-plane laminate properties and impact damage tolerance, advanced modelling techniques - potentially accommodating micro- and meso-scale damage phenomena-would be necessary together with the manufacturing and characterisation techniques presented. Such understanding would further help tailor the yarn-level micro-structure and fibre architecture of quasiUD laminates for the desired properties. On the other hand, it is worth noting that the manufacturing approach presented is cost-effective as commodity PP fibres with no surface treatment have been used for yarn-level hybridisation.

\section{Conclusions}

A combination of yarn-level fibre hybridisation and quasi-UD weave (i.e. low crimp architecture) is explored in order to balance in-plane mechanical properties and impact damage tolerance in composite woven laminates. The yarn-level hybridisation is successfully introduced by combining high-strength Sglass fibres and high-elongation PP fibres with commingling and core-wrapping processes (see Sec. 2.1). The hybrid yarns are used to produce a quasi-UD woven fabric with unbalanced warp and weft yarns, i.e. $5 \mathrm{H}$ satin with high linear density hybrid S-glas/PP warp and low linear density S-glass weft yarns (see Sec. 2.2). For comparison, the hybrid S-glass/PP yarns are also used for non-crimp (i.e. hybrid tow placement without weft yarns) and $5 \mathrm{H}$ satin woven fabric (i.e. with balanced S-glass/PP warp and weft yarns) laminates, and the S-glass yarns for non-crimp laminates (i.e. with non-hybrid tow placement without weft yarns). All the four laminate types are manufactured using vacuum-assisted resin infusion. Based on the in-plane laminate mechanical properties, measured using standard tensile and compresive tests (see Sec. 3.1), the low velocity impact and post-impact compression responses, characterised using standard drop-weight impact and compression-after-impact tests (see Sec. 3.2), and the sub-surface damage modes, investigated using sectioning and scanning electron microscopy (see Sec. 3.1-3.3), the following conclusions are drawn:

- In-plane tensile and compresive strengths: The yarn-level hybridisation and fibre architecture are observed to have a significant effect on the in-plane laminate tensile and compressive strengths. For instance, the in-plane tensile strengths of the S-glass/PP satin and S-glass/PP quasi-UD laminates show a significant difference, i.e. lower by $\sim 40 \%$ and $\sim 3 \%$, respectively, compared to that of the $S$ glass UD laminates (see Table 4). Moreover, the in-plane compressive strengths of the S-glass/PP satin and S-glass/PP quasi-UD laminates also show a similar trend, i.e. lower by $\sim 60 \%$ and $\sim 10 \%$, respectively, compared to that of the S-glass UD laminates (see Table 5). This clearly indicates that quasi-UD weaves similar to the one studied with reduced warp yarn crimp can successfully be used to enhance the in-plance tensile and compressive strengths.

- Impact and posit-impact compression response: It is seen that the yarn-level hybridisation and fibre architecture have significantly influenced the laminate response to low velocity impact and postimpact compression loading. For example, the projected damage area from C-scans hve shown that the damage in the S-glass/PP satin laminates is significanly lower than that in the S-glass/PP quasiUD laminates (see Fig. 8); on the other hand, the undamaged and post-impact compressive strengths are significantly higher in the S-glass/PP quasi-UD lamiantes compared to those of the S-glass/PP satin laminates (see Fig. 11a). In addition, as the post-impact compressive strength of the S-glass/PP quais-UD laminates is considerably higher that that of the S-glass UD lamiantes (see Fig. 11a), it also shows that the hybrid quasi-UD fabric used has significantly improved the laminate impact damage telerance, although a higher projected damage area is detected via C-scans.

- Micro- and macro-scale damage modes: The sub-surface damage observed clearly shows that the micro- and macro-scale damage modes can be noticeable altered with yarn-level hybridisation and fibre architecture. For example, the impact damage in the S-glass UD laminates shows multiple delaminations and fibre breakage, whereas delamination damage is significantly suppressed in the Sglass/PP laminates (see Fig. 10); and the presence of PP fibres seem to have introduced intra-yarn damage via PP fibre-matrix debonding (see Fig. 13). The post-impact compressive damage modes indicate that the failure behaviour of the laminates are sensitive to the damage modes introduced during impact as well as fibre architecture (e.g. the S-glass/PP quasi-UD laminates with reduced 
delamination have higher post-impact compressive strength in comparison with the S-glass/PP satin laminates, see Fig. 12).

As observed in the study, this approach of combining yarn-level hybridisation together with quasi-UD fibre architecture can effectively be used to introduce benign micro- and macro-scale damage modes, which absorb impact energy while suppressing multiple delaminations, and thus achieve a balance between the in-place laminate tensile and compressive strengths and impact damage tolerance. As a general outlook, the micro-structure and fibre architecture in such S-glass/PP quasi-UD laminates could potentially be tailored for achieving high compressive/tensile and post-impact residual compressive/tensile strengths by varying the parameters that define quasi-UD weaves (e.g. linear densities of warp and weft yarns, weave patterns, and yarn spacing) and hybrid yarns (e.g. S-glass and PP fibre volume fractions and their distributions).

\section{Acknowledgements}

The authors would like to acknowledge the Ministry of Higher Education and Scientific Research of Iraq for PhD funding to Hussein Dalfi, and EPSRC UK for EP/N021975/1.

\section{References}

[1] W. Cantwell and J. Morton, "The impact resistance of composite materials—a review," composites, vol. 22, pp. 347-362, 1991.

[2] M. Richardson and M. Wisheart, "Review of low-velocity impact properties of composite materials," Composites Part A: Applied Science and Manufacturing, vol. 27, pp. 1123-1131, 1996.

[3] R. O. Ritchie, "The conflicts between strength and toughness," Nature Materials, vol. 10, pp. 817-822, Nov 2011.

[4] U. G. K. Wegst, H. Bai, E. Saiz, A. P. Tomsia, and R. O. Ritchie, "Bioinspired structural materials," Nature Materials, vol. 14, pp. 23-36, Jan 2015.

[5] K. Katnam, L. Da Silva, and T. Young, "Bonded repair of composite aircraft structures: A review of scientific challenges and opportunities," Progress in Aerospace Sciences, vol. 61, pp. 26-42, 2013.

[6] A. Mouritz, M. Bannister, P. Falzon, and K. Leong, "Review of applications for advanced threedimensional fibre textile composites," Composites Part A: applied science and manufacturing, vol. 30, pp. 1445-1461, 1999.

[7] J. Cao, R. Akkerman, P. Boisse, J. Chen, H. Cheng, E. De Graaf, J. Gorczyca, P. Harrison, G. Hivet, and J. Launay, "Characterization of mechanical behavior of woven fabrics: experimental methods and benchmark results," Composites Part A: Applied Science and Manufacturing, vol. 39, pp. 1037-1053, 2008.

[8] H. Chen and B. Jang, "Failure mechanisms of 2-D and 3-D woven fiber reinforced polymer composites," Polymer composites, vol. 16, pp. 125-134, 1995.

[9] T. J. Kang and C. Kim, "Energy-absorption mechanisms in Kevlar multiaxial warp-knit fabric composites under impact loading," Composites Science and Technology, vol. 60, pp. 773-784, 2000.

[10] S. V. Lomov, D. Ivanov, T. Truong, I. Verpoest, F. Baudry, K. V. Bosche, and H. Xie, "Experimental methodology of study of damage initiation and development in textile composites in uniaxial tensile test," Composites Science and Technology, vol. 68, pp. 2340-2349, 2008.

[11] G. Bibo and P. Hogg, "Influence of reinforcement architecture on damage mechanisms and residual strength of glass-fibre/epoxy composite systems," Composites science and technology, vol. 58, pp. 803-813, 1998.

[12] J. Baucom and M. Zikry, "Low-velocity impact damage progression in woven E-glass composite systems," Composites Part A: Applied Science and Manufacturing, vol. 36, pp. 658-664, 2005.

[13] D. D. Cartié, G. Dell'Anno, E. Poulin, and I. K. Partridge, "3D reinforcement of stiffener-to-skin T-joints by Z-pinning and tufting," Engineering Fracture Mechanics, vol. 73, pp. 2532-2540, 2006.

[14] K. Dransfield, C. Baillie, and Y.-W. Mai, "Improving the delamination resistance of CFRP by stitching-a review," Composites Science and Technology, vol. 50, pp. 305-317, 1994.

[15] K. T. Tan, N. Watanabe, Y. Iwahori, and T. Ishikawa, "Effect of stitch density and stitch thread thickness on compression after impact strength and response of stitched composites," Composites Science and Technology, vol. 72, pp. 587-598, 2012.

[16] X. Zhang, L. Hounslow, and M. Grassi, "Improvement of low-velocity impact and compression-afterimpact performance by z-fibre pinning," Composites Science and Technology, vol. 66, pp. 2785-2794, 2006.

[17] N. Zhao, H. Rödel, C. Herzberg, S.-L. Gao, and S. Krzywinski, "Stitched glass/PP composite. Part I: Tensile and impact properties," Composites Part A: Applied Science and Manufacturing, vol. 40, pp. 635-643, 2009. 
[18] P. Potluri, P. Hogg, M. Arshad, D. Jetavat, and P. Jamshidi, "Influence of fibre architecture on impact damage tolerance in 3D woven composites," Applied Composite Materials, vol. 19, pp. 799-812, 2012.

[19] C. Chen, R. S. Justice, D. W. Schaefer, and J. W. Baur, "Highly dispersed nanosilica-epoxy resins with enhanced mechanical properties," Polymer, vol. 49, pp. 3805-3815, 2008.

[20] L. Daelemans, S. van der Heijden, I. De Baere, H. Rahier, W. Van Paepegem, and K. De Clerck, "Damage-Resistant Composites Using Electrospun Nanofibers: A Multiscale Analysis of the Toughening Mechanisms," Acs Applied Materials \& Interfaces, vol. 8, pp. 11806-11818, May 112016.

[21] P. J. Hogg, "Toughening of thermosetting composites with thermoplastic fibres," Materials Science and Engineering: A, vol. 412, pp. 97-103, 2005.

[22] T. Hsieh, A. Kinloch, K. Masania, J. S. Lee, A. Taylor, and S. Sprenger, "The toughness of epoxy polymers and fibre composites modified with rubber microparticles and silica nanoparticles," Journal of materials science, vol. 45, pp. 1193-1210, 2010.

[23] J.-K. Kim, D. Mackay, and Y.-W. Mai, "Drop-weight impact damage tolerance of CFRP with rubbermodified epoxy matrix," Composites, vol. 24, pp. 485-494, 1993.

[24] X. Xu, Z. Zhou, Y. Hei, B. Zhang, J. Bao, and X. Chen, "Improving compression-after-impact performance of carbon-fiber composites by CNTs/thermoplastic hybrid film interlayer," Composites Science and Technology, vol. 95, pp. 75-81, 2014.

[25] M. T. Dehkordi, H. Nosraty, M. M. Shokrieh, G. Minak, and D. Ghelli, "The influence of hybridization on impact damage behavior and residual compression strength of intraply basalt/nylon hybrid composites," Materials \& Design, vol. 43, pp. 283-290, 2013.

[26] M. Alsaadi, A. Erkliğ, and H. Alrawi, "Effect of S-glass fabric on the mechanical characteristics of a hybrid carbon/aramid fabric reinforced epoxy composites," Materials Research Express, vol. 4, p. 055304, 2017.

[27] I. M. Daniel and J. S. Fenner, "Hybrid Nano/Microcomposites for Enhanced Damage Tolerance," Experimental and Applied Mechanics, Volume 6, pp. 259-265, 2011.

[28] Y. Swolfs, L. Gorbatikh, and I. Verpoest, "Fibre hybridisation in polymer composites: a review," Composites Part A: Applied Science and Manufacturing, vol. 67, pp. 181-200, 2014.

[29] C. Thanomsilp and P. J. Hogg, "Penetration impact resistance of hybrid composites based on commingled yarn fabrics," Composites Science and Technology, vol. 63, pp. 467-482, 2003.

[30] E. Selver, P. Potluri, P. Hogg, and C. Soutis, "Impact damage tolerance of thermoset composites reinforced with hybrid commingled yarns," Composites Part B: Engineering, vol. 91, pp. 522-538, 2016.

[31] A. J. Kinloch and A. C. Taylor, "The mechanical properties and fracture behaviour of epoxy-inorganic micro- and nano-composites," Journal of Materials Science, vol. 41, pp. 3271-3297, Jun 2006.

[32] K. Vallons, G. Adolphs, P. Lucas, S. V. Lomov, and I. Verpoest, "Quasi-UD glass fibre NCF composites for wind energy applications: a review of requirements and existing fatigue data for blade materials," Mechanics \& Industry, vol. 14, pp. 175-189, 2013.

[33] Y. D. Kergomard, J. Renard, A. Thionnet, and C. Landry, "Intralaminar and interlaminar damage in quasi-unidirectional composite structures: Experimental analysis," Composites Science and Technology, vol. 70, pp. 1504-1512, Sep 302010.

[34] B. Wang, K. Maekawa, N. Uda, K. Ono, and H. Nagai, "Compressive failure analysis of quasi-isotropic composite laminates fabricated with quasi-unidirectional woven fabric," Journal of Composite Materials, vol. 50, pp. 231-241, Jan 2016.

[35] J. Prichard and P. Hogg, "The role of impact damage in post-impact compression testing," Composites, vol. 21, pp. 503-511, 1990. 